NBER WORKING PAPER SERIES

GOALS AND PLANS IN PROTECTIVE DECISION MAKING

David H. Krantz

Howard C. Kunreuther

Working Paper 12446

http://www.nber.org/papers/w12446

NATIONAL BUREAU OF ECONOMIC RESEARCH

1050 Massachusetts Avenue

Cambridge, MA 02138

August 2006

We thank Xin Piao for her help in many phases of our thinking about protective decisions, Alex Leeds for insightful comments on two earlier manuscript drafts, and Mark Pauly for much advice relating to insurance anomalies. Financial support from NSF SES \# 0136872, from the Columbia University Center for Decision Sciences, and from the Wharton Risk Management and Decision Processes Center is gratefully acknowledged. The views expressed herein are those of the author(s) and do not necessarily reflect the views of the National Bureau of Economic Research.

(C2006 by David H. Kranz and Howard C. Kunreuther. All rights reserved. Short sections of text, not to exceed two paragraphs, may be quoted without explicit permission provided that full credit, including () notice, is given to the source. 
Goals and Plans in Protective Decision Making

David H. Krantz and Howard C. Kunreuther

NBER Working Paper No. 12446

August 2006

JEL No. G22, H23, H44

\begin{abstract}
$\underline{\text { ABSTRACT }}$
Protective decisions are often puzzling. Among other anomalies, people insure against non-catastrophic events, underinsure against catastrophic risks, and allow extraneous factors to influence insurance purchases and other protective decisions. Neither expected utility theory nor prospect theory can explain these anomalies satisfactorily. We propose a constructed-choice model for general decision making. The model departs from utility theory and prospect theory in its treatment of multiple goals and it suggests several different ways in which context can affect choice. To apply this model to the above anomalies, we consider many different insurance-related goals, organized in a taxonomy, and we consider the effects of context on goals, resources, plans and decision rules. The paper concludes by suggesting some prescriptions for improving individual decision making with respect to protective measures.
\end{abstract}

David Krantz

Columbia University

419A Schermerhorn

Mail Code 5501

New York, NY 10027

Howard Kunreuther

Operations and Information Management

The Wharton School

University of Pennsylvania

Philadelphia, PA 19104-6366

and NBER

kunreuther@wharton.upenn.edu 


\title{
GOALS AND PLANS IN PROTECTIVE DECISION MAKING
}

\author{
David H. Krantz and Howard C. Kunreuther
}

\section{Introduction}

Many insurance-related decisions appear, at first glance, to be suboptimal. For example, many people pay added premiums that seem excessive to obtain automobile collision insurance with a low deductible. To make matters worse, some decide not to file a claim following a small accident whose cost could largely be reimbursed via this low deductible ${ }^{1}$ : they fear that a claim would lead to increased premiums in the next and succeeding years.

A rather different example emerged after the passage of the National Flood Insurance Program in 1968. Insurance coverage against water damage from flooding was offered both to homeowners and to commercial enterprises in high hazard areas at subsidized low rates. Yet there was limited interest in purchasing this coverage despite the subsidy and despite the potential for catastrophic losses (Kunreuther, 1978).

As a third example, many people are prepared to pay considerably more to insure possessions that they find very attractive than to insure possessions toward which they feel neutral or negative (Hsee and Kunreuther, 2000). If such a possession is needed, then it must be replaced after loss or damage. The replacement cost remains the same, independent of one's positive or negative feelings toward the object. Therefore the insurance offers exactly the same financial benefit, independent of feelings, and it is hard to find a financial reason to pay more for insuring the attractive object.

\section{Types of anomaly}

Three broad classes of insurance anomaly that we consider in this paper are illustrated by the above examples. One class of anomalous behavior is insuring against a non-catastrophic loss. A second type is underinsuring against a truly catastrophic loss. The third category is considering factors that have little or nothing to do with magnitudes or probabilities of financial loss when making insurance-purchase decisions.

(1) Insuring against non-catastrophic losses

Many insurance contracts have a "deductible" amount whereby only losses in excess of that amount will be reimbursed. Thus, with a $\$ 200$ deductible, a $\$ 900$ loss will result in a reimbursement of $\$ 700$, a $\$ 300$ loss will yield only $\$ 100$, and a $\$ 100$ loss will not be reimbursed at all. Usually, the additional premium for a low deductible is set high enough so that the insurer has a positive expected value; thus, the insurance purchaser must have a negative expected value. On the average, individuals lose money by purchasing insurance with low rather than high deductibles. Nonetheless, low deductibles are popular, and a common strategy is to purchase the lowest possible deductible (Kunreuther \& Pauly, 2006). A number of years ago the Insurance Commissioner of Pennsylvania, Herbert Denenberg, mandated at least a $\$ 100$ deductible (rather than a $\$ 50$ deductible) for automobile collision policies. Although the plan purportedly saved consumers millions of dollars it was opposed by the public and had to be rescinded (Cummins, et al., 1974).

Apart from seeking low deductibles, people insure against other non-catastrophic losses:

1. The term "pseudodeductible" was introduced by Braun, Bradlow, Fader and Kunreuther, 2005, referring to a low deductible that is paid for but not used when it could be. 
they may insure mailed packages with only modest monetary value, or may purchase insurance to cover replacement of a lost contact lens. If one insures against many non-catastrophic losses, one is nearly certain to come out behind financially, as compared with a strategy of not insuring against any of those losses. This follows from the law of large numbers, together with fact that the insurance contracts have negative expected value. One can summarize by saying that people should self-insure against non-catastrophic losses, but they fail to do so.

\section{(2) Underinsuring against truly catastrophic losses}

Many people fail to purchase protection against low-probability high-impact events unless they are required to do so. Examples are the financial catastrophes that can arise from a destructive earthquake or flood, from a prolonged major illness, or from a large adverse civil judgment. For such events, the pool of individuals at risk is often large. Therefore, although the probability is low for each, some people will inevitably be victims. For those who are affected, the financial protection from insurance can make the difference between recovery of one's life pattern after the negative event, versus very deep and continuing difficulties. Since the risk pool is large, the financial risk can be spread widely, and therefore the cost of insurance for each person can be relatively low compared to the potential for a catastrophic loss should an untoward event occur. In some cases, subsidies for insurance spread the cost even more widely, e.g., to all taxpayers. Failure to budget moderate amounts to protect against such financial catastrophe seems imprudent.

\section{(3) Sensitivity to "extraneous" factors}

We group together here behavioral phenomena in which insurance purchase is influenced by factors that are irrelevant or extraneous, in the sense that they do not affect the financial benefits of insurance, its monetary cost, or the probability of an adverse event. Factors that are often (but not always) extraneous, in this sense, include: (i) the positive or negative affect attached to an object or event; (ii) recent experience of events such as flooding; (iii) what friends and relatives have decided to do; and (iv) minor transaction costs.

\section{Psychological explanations for anomalies}

Below, we consider a variety of explanations. Here, we focus just on two: extra-financial goals and context effects. Individuals consider multiple goals, not just financial ones in making insurance decisions. As a result of these multiple goals people may purchase insurance that appears to be unattractive from a financial point of view but satisfies other needs. In particular contexts, the salience of some goals may be very high or very low; if one attends only to goals that are currently very salient, one may purchase insurance that is not really needed or neglect protective measures that are needed.

Consider the example of flight insurance, which typically costs $\$ 5$ to $\$ 10$ per $\$ 100,000$ of coverage. By contrast, a general accidental death insurance policy that offers $\$ 500,000$ for death in any common-carrier accident (including commercial airplane flights), plus many other benefits (injury, automobile accident, etc.) can be obtained for about $\$ 12$ per month for one person. Thus, coverage for $\$ 500,000$ for a single airplane flight is much cheaper if one gets the general insurance policy for a full month, rather than insurance for a specific flight. However, purchasing flight insurance at the airport may, for some people, provide "peace of mind" and for the purpose of such anxiety reduction it may be preferred to drinking alcohol at an airport bar. Alternatively, a person might make the purchase to demonstrate that she cares for her loved ones. Such extrafinancial goals might make the flight insurance worth the cost.

We would not want to assert, however, that purchase of flight insurance is definitely optimal 
in view of these extra-financial goals. The latter goals are made salient in the airport context; flight insurance would probably be much less popular if it were sold at the local grocery store. Someone who thinks about the risks of air travel in a broader temporal frame might well choose to purchase general accident insurance, and might achieve peace of mind just by recalling, at the time of any single flight, that she is insured.

The paper is organized in the following manner. The next section discusses ways of incorporating multiple goals into quantitative models of choice: we contrast a standard utility maximization framework with a model of constructed choice, and argue that the latter offers several advantages. Section 3 presents a taxonomy of insurance-related goals. Section 4 uses this classification to help explain anomalies, such as those noted above, in ways that differ substantially from the expected-utility framework and from prospect theory. The paper concludes with a set of prescriptive implications of a model of protective activities based on multiple goals and constructed choice.

\section{Goal-based Models of Choice}

Most plans are designed to achieve multiple goals; and protective plans are no exception. For example, a plan to purchase fire and theft insurance (on a home, say, or on the contents of a rented apartment) may be designed to satisfy as many as seven goals simultaneously: (i) reducing the chances of a catastrophic loss, (ii) reducing anxiety about risks of fire and theft, (iii) avoiding regret and/or providing consolation in case a loss occurs, (iv) satisfying requirements stated by a bank or by a landlord, (v) presenting the appearance of prudence to others who will learn about the insurance purchase, (vi) maintaining ones relationship with an insurance agent, and (vii) avoiding highly burdensome insurance premium payments. The importance of these goals obviously varies with the decision maker, but may also be affected temporarily by contextual variables. Someone grappling with the problem of keeping monthly payments affordable may, in that context, think only about two goals: satisfying the risk-reduction requirements of the bank that holds the mortgage loan (goal iv above), and minimizing the cost of insurance (goal vii). If the same person has just inherited valuable works of art, she may think chiefly about reducing anxiety (goal ii) and avoiding regret (goal iv).

There is a subtle and important question about how such multiple goals should be represented in theories of human decision making and in prescriptive principles aimed at better decisions. If goals are viewed as stable, then tradeoffs among different goals may well be represented by a multi-attribute utility function. Decision making can then be viewed as an attempt to maximize expected multi-attribute utility-albeit limited by bounds on human knowledge and abilities. In this framework there is nothing counternormative about including non-financial goals in the utility function. If, on the other hand, context strongly influences what goals are considered and how they are traded off, then it may be impossible to view decision making as an attempt to maximize multi-attribute utility. A "utility function" would be context dependent, and indeed, might vary with the set of options available to the decision maker (which form part of the context). The description of human decision making might focus on what goals are considered at all, rather than about stable trade-offs among different attributes. A constructed choice that is heavily based on some particular goal might be viewed as suboptimal, if that goal turns out to get little or no weight in other contexts encountered by the decision maker.

The idea that preferences are constructed, rather than revealed, emerged from many lines of research in the late 1980s and early 1990s (e.g., Tversky, Sattath \& Slovic, 1988, Tversky, Slovic \& Kahneman, 1990, Chapman \& Johnson, 1995) and was well characterized by Slovic 
(1995). This idea is more or less taken for granted in current psychological work on decision making (e.g., Sedikides, Ariely \& Olsen,1999; Zhang \& Markman, 2001). In order to apply the idea systematically to protective decision making with multiple goals, and in order to consider its prescriptive implications, it seems necessary to develop a model of context-dependent choice that runs as parallel as possible to the theory of expected utility. We do this in the next two subsections.

\section{Multiple goals and utility maximization}

In traditional decision theory, a choice among several alternative plans, each with multiple goals, is usually cast in the framework of multi-attribute utility theory (Debreu, 1960; Krantz, Luce, Suppes \& Tversky, 1971; Keeney \& Raiffa, 1976). To incorporate uncertainty, a decision problem is often represented as a matrix (Savage, 1954): the rows represent possible actions or strategies for the decision maker, the columns represent possible events that could occur, and the entry in any cell of the matrix (any given strategy-event combination) is a multi-attribute outcome, composed of all goals that will be achieved if that particular strategy is selected by the decision maker and that particular event happens to occur.

Table 1 depicts aspects of this model in an abstract form and indicates how the model is used for measurement and decision making. The columns in Table 1 are a partition of possible events. The notation $o_{i j}$ for the cell entries conceals the complications associated with evaluating outcomes consisting of multiple attributes. (See Keeney and Raiffa 1976 for a detailed discussion of this point.) The selected strategy is one that maximizes expected utility. The expected utility equation, shown at the bottom of Table 1, serves as the basis for measurement of outcome utilities $u_{i j}$ and subjective probabilities $p_{j}$.

\section{Table 1: General strategy/event structure for decision making under uncertainty}

\begin{tabular}{l|llll}
\multicolumn{2}{l}{$\begin{array}{l}\text { matrix entries are outcomes for different strategies, conditional on events } \\
\text { Possible }\end{array}$} & \multicolumn{4}{c}{ Possible Events (mutually exclusive and exhaustive) } \\
Strategies & $E_{1}$ & $E_{2}$ & $\ldots$ & $E_{n}$ \\
& $o_{11}$ & $o_{12}$ & $\ldots$ & $o_{1 n}$ \\
\hline strategy 1 & $o_{22}$ & $\ldots$ & $o_{2 n}$ \\
strategy 2 & $o_{21}$ & $o_{22}$ & & \\
$\ldots$ & $\ldots$ & $o_{m 2}$ & $\ldots$ & $o_{m n}$ \\
strategy $\mathrm{m}$ & $o_{m 1}$ & & & \\
\hline
\end{tabular}

$$
\begin{array}{cl}
\text { events have subjective probabilities } & p_{j}=\operatorname{prob}\left(E_{j}\right) \\
\text { outcomes have subjective values } & u_{i j}=\operatorname{value}\left(o_{i j}\right) \\
u_{i j} \text { may be integrated across multiple attributes of } o_{i j}
\end{array}
$$

multi-attribute utility is integrated across uncertain events

$$
U(\text { strategy } i)=\sum_{j=1}^{n} p_{j} u_{i j}
$$


This framework can be used for measurement of $p_{j}$ and $u_{i j}$, assuming the functional forms for multi-attribute utility and expectation (Savage, 1954; Krantz, Luce, Suppes \& Tversky, 1971; Koebberling \& Wakker, 2004). Alternatively, given values of $p_{j}$ and $u_{i j}$, the model can be used to find the strategy that maximizes expected utility and thus aid complex decisions.

There is a vast literature devoted to commentary on this subjective expected (multiattribute) utility (SEMAUT) framework. We make no attempt to summarize the debates about SEMAUT, but we note three points, for purpose of contrast with the framework developed in the next subsection.

First, the SEMAUT mechanism entails that choices are transitive, because the ordering of $U$ (strategy) is a numeric ordering. Transitivity is often viewed as the most fundamental of normative principles of choice, but it is violated systematically and predictably by at least two quite different and commonly used choice mechanisms: majority voting in social choice (Condorcet, 1785; Arrow, 1951) and additive combination of within-attribute differences (Tversky, 1969). Moreover, transitivity of pairwise choice can easily be violated through contextdependent decisions: a decision maker can choose option A over option B in one context, and $\mathrm{B}$ over $\mathrm{C}$ in a second context, and yet choose $\mathrm{C}$ over $\mathrm{A}$ in a third context. We return later to the various ways in which transitivity fails for individual decision making, and suggest that alternative decision rules, which permit intransitivity, can be used without violating any compelling normative principle.

Second, the SEMAUT framework demands rather complex utility measurements for the conjunctions of different goals that are bundled together within one outcome $o_{i j}$. Multi-attribute utility may be hard to measure for the mixture of goals that are involved in protective decision making. We illustrate this point by an example (Table 2), in which the framework of Table 1 is instantiated for a simplified version of a decision concerning flood insurance. Table 2 gives a strategy/event matrix with only two strategies and four events. We achieve this simplification by assuming that only one insurance policy is available, thus the only two strategies are to purchase insurance or not. Each row of the matrix is wide enough to encompass several different outcome components (financial cost, hassles, various feelings) listed as subheadings. The columns distinguish four events: $E_{1}$, no flood; $E_{2}$, a flood in which one manages to avoid major property damage; $E_{3}$, a flood that leads to major property damage; and $E_{4}$, a destructive flood that causes catastrophic property damage. We treat $E_{1}$ through $E_{4}$ as mutually exclusive and exhaustive. For concreteness we assume that these four events have respective annual probabilities $85 \%, 9 \%$, $4 \%$, and $2 \%$. Such probabilities could be the output of an elaborate scientific model, or might represent the decision maker's best (subjective) judgment. The utility assigned to a specific outcome would depend on the levels of the components, i.e., the level of financial cost, hassles, anxiety, etc. 
Table 2: Strategy/event matrix for purchase of flood insurance

\begin{tabular}{|c|c|c|c|c|}
\hline \multirow[b]{2}{*}{ event description } & \multicolumn{4}{|c|}{ Events } \\
\hline & $\begin{array}{c}E_{1} \\
\text { no flood }\end{array}$ & $\begin{array}{c}\qquad E_{2} \\
\text { flood causes } \\
\text { little damage }\end{array}$ & $\begin{array}{c}E_{3} \\
\underset{\text { damaging }}{\text { flood }}\end{array}$ & $\begin{array}{c}E_{4} \\
\text { destructive } \\
\text { flood }\end{array}$ \\
\hline event probability & .85 & .09 & .04 & .02 \\
\hline $\begin{array}{l}\text { strategy 1: } \\
\text { purchase flood insurance }\end{array}$ & & & & \\
\hline outcome components & & & & \\
\hline financial cost & premium & premium & premium & premium \\
\hline hassles & none & minor & major & great \\
\hline chronic flood-related anxiety & none & none & none & none \\
\hline acute anxiety (at flood) & none & little & little & little \\
\hline other feelings & regret & justification & justification & justification \\
\hline $\begin{array}{l}\text { strategy } 2 \text { : } \\
\text { no insurance }\end{array}$ & & & & \\
\hline outcome components & & & & \\
\hline financial cost & none & small & large & catastrophic \\
\hline hassles & none & minor & major & great \\
\hline chronic flood-related anxiety & some & some & some & some \\
\hline acute anxiety (at flood) & none & much & much & much \\
\hline other feelings & justification & relief & major regret & vast regret \\
\hline
\end{tabular}

To use this matrix as a decision support tool, one would need to evaluate subjectively some rather complicated conjunctions of consequences: for example, if one does not purchase insurance, and there is a damaging flood $\left(E_{3}\right)$, how will one feel about having suffered some long-term anxiety about a possible flood, then acute anxiety as the waters rise, coupled with major hassles, major regret at not being insured, and large financial losses? Does it make sense to evaluate each of these disutilities separately and then just add them up numerically, before multiplying by the $4 \%$ probability of $E_{3}$ ? The validity of such a procedure would not be obvious, but what are the appealing alternatives?

\section{Putting goals first: Toward a theory of context-dependent choice}

The same flood-insurance decision can be represented by a rather different sort of matrix, in which the rows have similar meaning but the columns are specified by the goals that might enter 
into the decision process ${ }^{2}$. We call the rows plans, rather than strategies (for reasons that will be discussed below), and call this representation a plan/goal matrix.

\section{Table 3: Plan/goal matrix for purchase of flood insurance}

\begin{tabular}{l||c|ccc|cc|cc}
\multicolumn{1}{c|}{} & \multicolumn{7}{c|}{ Goals } \\
Plans & $\begin{array}{c}\text { feel } \\
\text { justified }\end{array}$ & $\begin{array}{l}\text { avoid } \\
\text { small } \\
\text { loss }\end{array}$ & $\begin{array}{c}\text { avoid } \\
\text { major } \\
\text { loss }\end{array}$ & $\begin{array}{c}\text { avoid } \\
\text { catastrophic } \\
\text { loss }\end{array}$ & $\begin{array}{c}\text { avoid } \\
\text { chronic } \\
\text { anxiety }\end{array}$ & $\begin{array}{c}\text { avoid } \\
\text { acute } \\
\text { anxiety }\end{array}$ & $\begin{array}{c}\text { avoid } \\
\text { major } \\
\text { regret }\end{array}$ & $\begin{array}{c}\text { avoid } \\
\text { vast } \\
\text { regret }\end{array}$ \\
\hline \hline $\begin{array}{l}\text { plan 1: } \\
\text { purchase } \\
\text { flood insurance }\end{array}$ & .15 & 0 & 1 & 1 & 1 & mostly & 1 & 1 \\
\hline $\begin{array}{l}\text { plan 2: } \\
\text { no insurance }\end{array}$ & .85 & .85 & .94 & .98 & 0 & .85 & .94 & \\
\hline
\end{tabular}

In Table 3, most of the outcome components shown in Table 2 have been transformed into goals, especially, losses or emotions to be avoided. Eight possible goals are shown-not all may be active or important for a given decision maker. Goals relating to avoidance of hassles could also be included (they are outcome components in Table 2), but we omit them here because the hassles, minor or otherwise, are unavoidable if a flood occurs, whether or not one purchases insurance. Thus, they are irrelevant to the decision. The rows are narrow in Table 3, because in this example, the conditions under which a given plan achieves each goal can mostly be stated as numeric probabilities, by cumulating the event probabilities from Table 2 appropriately.

For example, the decision maker will avoid catastrophic financial loss and vast regret, under the no-insurance plan, provided that there is no destructive flood, an event with probability $.85+.09+.04=.98$. Note that this cumulation of events relative to a particular goal is akin to the formalism of cumulative prospect theory (Tversky \& Kahneman, 1992), and indeed, the model we present here is motivated by that theory.

Superficially, the change from Table 2 to Table 3 could be viewed as just a rearrangement. For example, in Table 2, under strategy 1, the utility of "feel justified" would be multiplied by $.09+.04+.02=.15$, corresponding to the flood events $E_{2}, E_{3}, E_{4}$; while in Table 3, under plan 1 , the value of attaining the goal "feel justified" would again be multiplied by the weight factor .15. In other words, we are just taking the components of multiattribute utility from Table 2 and turning them into goal values for the columns of Table 3, and we are cumulating the event probabilities from the columns of Table 2 and inserting them appropriately as matrix entries in Table 3.

There are several reasons why the change from Table 2 to Table 3 is much more farreaching than would be implied by such a rearrangement. Before discussing this change further,

2. Much previous work has been devoted to goals that serve as reference points on a continuum, e.g., aspiration level (Fischer, Carmon, Ariely \& Zauberman, 1999; Heath, Larrick \& Wu, 1999; See, Heath \& Fox, 2006; Shapira, 1995). The present use of the goal concept is intended to include such cases, as we discuss further in connection with prospect theory below. Our concept is broader, however, and derives from social psychology (Lewin, 1951) and from cognitive theory (Newell, 1990). 
we give the more general abstract form of the plan/goal matrix.

Table 4 depicts the plan/goal structure in a manner as close as possible to the strategy/event structure of Table 1. As already mentioned in connection with Table 3, we let the rows represent plans rather than strategies, for a reason to be discussed. The major differences from Table 1 are that here, goals rather than events define the columns, and the entries in the cells are decision weights rather than multi-attribute outcomes.

\section{Table 4: General plan/goal structure for decision making}

\begin{tabular}{l|lccc}
\multicolumn{1}{l}{ matrix entries are decision weights for different goals, conditional on plans } \\
$\begin{array}{l}\text { Possible } \\
\text { Plans }\end{array}$ & $G_{1}$ & $G_{2}$ & $\ldots$ & $G_{n}$ \\
& $G_{11}$ & $w_{12}$ & $\ldots$ & $w_{1 n}$ \\
plan 1 & $w_{11}$ & $w_{22}$ & $\ldots$ & $w_{2 n}$ \\
plan 2 & $w_{21}$ & & & \\
$\ldots$ & $\ldots$ & $w_{m 2}$ & $\ldots$ & $w_{m n}$ \\
plan m & $w_{m 1}$ & & & \\
\hline
\end{tabular}

$$
\begin{array}{lrl}
\text { goals have subjective values } & v_{j}=v\left(G_{j}\right) \\
\text { plans } \rightarrow \text { decision weights for each goal } & w_{i j}=w\left(G_{j} \mid \text { plan } i\right)
\end{array}
$$

plan $i$ is evaluated in terms of the $v_{j}$ and $w_{i j}$.

\section{The plan/goal structure in constructed choice}

We will discuss five differences between the plan/goal structure depicted in Table 4 and the strategy/event structure given in Table 1 to represent SEMAUT. What emerges overall, however, is that the different structures suggest different questions to be asked in analyzing a decision problem.

Our first point is seen most easily by contrasting Tables 2 and 3 in the matter of flood insurance. The SEMAUT structure incorporates feelings at the cost of asking difficult questions about utility of multi-attribute outcomes compounded from heterogeneous elements-financial outcomes plus an assortment of different feelings that may arise. The questions may be difficult because the underlying utilities are fictitious from a psychological viewpoint: people are highly uncertain about their tradeoffs among such heterogeneous elements. When we put goals first, we drop such artificial compounds. Of course, there exist natural compound goals. Simple examples abound: bread-and-butter, butter-or-margarine, etc. Some of the columns of a plan/goal matrix can represent such natural conjunctions or disjunctions of goals. An example of a natural compound protective goal would be insuring against both water damage and wind damage, in a coastal zone subject to hurricanes. Unfortunately, insurers are reluctant to offer a simple plan that achieves this compound; property owners are forced to construct a complex insurance plan for 
this purpose (Kunreuther, 2006). Our main point is that the plan/goal formalism does not force one to create extraneous compounds. Difficult tradeoffs among heterogeneous goals are still present in the plan/goal setup, but they are taken into consideration at the level of decision rules for selecting among competing plans, not at the level of basic utility measurement.

Second, the goals considered by the decision maker are context dependent, as are their subjective values $v(G)$. Context elements, including some of the plans available as options, can suggest goals that might not otherwise be considered. This is almost standard when one goes to a new restaurant, reputed to be excellent: the menu offers plans, or components that can be put together into plans; seeing what is available often leads the diner to adopt a goal that is entirely novel (ostrich livers in garlic butter) or to change the value $v_{j}$ for an existing goal (e.g., a lowcalorie diet). The same can be true for protective goals: one can adopt a new goal in light of a protective device offered for sale in a catalog, or in light of an innovative provision offered in an insurance contract. Valuation of goals can also change with context: for example, a goal toward which only slight movement seems possible from the available plans, may be downweighted in importance in the decision process.

An innovative plan may be selected because it seems more likely that an important goal can be achieved, i.e., the decision weight $w$ for that goal is high, for the plan in question. Here, however, we are making a different point: it is not merely that the decision weight $w$ is high, rather, it is the value $v$ for the goal that is changed when the particular plan (or any other context element) makes that goal salient. In the extreme, the goal might be one that was entirely unknown tothe decision maker before the context made it salient. We discuss this further below, in relation to Tversky-type intransitivities.

Third, since goals are highlighted in this representation, the uncertain events on which outcomes depend are relegated to the cells of the matrix. In Tables 3 and 4 we show probabilities or decision weights in the cells. The thinking underlying the decision weights is hidden entirely in the matrix representation, but of course it has to be made explicit when one uses this model. For example, the probabilities in Table 3 are cumulative sums of probabilities for an ordered series of events. In other settings, decision weights may arise from subjective support, i.e., the weighing of evidence (Tversky \& Koehler, 1994). Decision weights may also be affected by poor timing in the delivery of an outcome (e.g., untoward delay) or by incompleteness. This is illustrated by the entry "mostly" in Table 3 : it is not a probability but a degree of approximation to a goal, since one may not entirely escape acute anxiety over an impending flood by purchasing insurance, but one might greatly reduce it.

Fourth, Table 4 allows, but does not commit to a sum-of-products decision rule. In contrast, SEMAUT commits to a decision rule that orders strategies on the basis of

$$
U(\text { strategy } i)=\sum_{j=1}^{n} p_{j} u_{i j},
$$

Table 4 merely states that plan $i$ is evaluated in terms of goal values $v_{j}$ and decision weights $w_{i j}$. Below we discuss three classes of rules that we think play important roles in some types of decisions, all of them different from a sum-of-products rule. Note also that even if a sum-ofproducts rule is used, and is formally identical to the calculation of SEMAUT, because the $u_{i j}$ are additive multi-attribute utilities and the $w_{i j}$ are sums of atomic probabilities, the plan/goal framework is not equivalent to SEMAUT because the $v_{j}$ can change with context. Among other things, such context-dependence allows intransitivity of pairwise choice.

Our final comment relates to the substitution of "plan" for "strategy." In many cases, nothing is gained or lost by this change: in non-technical contexts, the two words are more or less synonyms. However, strategy already has a technical meaning in game theory, where it refers to 
a choice element for a game represented in normal (rather than extensive) form. That is, a strategy specifies exactly what the player will do in every circumstance that arises in the course of playing a game. This technical meaning is one that we emphatically do not wish to convey: we view plans as hierarchically organized, containing new decision nodes within them. For example, a plan to buy insurance would not normally include a specification of how to travel from one's home or workplace to an insurance agent's office. If the latter trip becomes necessary, a new decision process is set in motion to decide how to get there. Similarly, chess players (including grandmasters) select plans, with room for improvisation; they cannot select strategies, because the number of branches in the chess tree is much too large to allow even one game-theoretic strategy to be specified fully.

Another reason for introducing the term plan is to call attention to the fact that there is a real problem of level of specificity in the entire field of decision making. What is actually decided (consciously or unconsciously) and what is simply done pursuant to a plan already adopted (with minor parametric adjustments guided by external circumstances)? We confront this problem by making explicit the assumption that decision making is plan selection. Executing a plan usually require many actions, but may not require any new decisions. Sometimes, a plan leaves open a choice of subplans at some critical juncture, and in that case, there is an additional decision that has to be made.

The distinction between plan selection and plan execution is related to that between categorical and continuous perception. We perceive objects on continua (size, distance, weight, friendliness, etc.) in order to adjust existing plans to reality, but we categorize objects in order to decide what new plan (or new subordinate plan) should be chosen. For example, one may be concerned about fire hazard from old papers in a storage room, and may select a plan that involves spending an afternoon clearing them out. One has categorized the papers as sufficiently hazardous to adopt a goal of greatly reducing the hazard and one selects a plan that has a good chance of achieving it. When it comes to executing the plan, details will vary depending on a more continuous perceptual response. If one is over half done after one hour's work, one begins to modify the plan so as to make good use of the time gained by finishing early. Similarly, a plan to seek insurance may be triggered by categorization of a financial risk as too great to ignore, but the execution of the search plan will vary with countless details.

We choose the word "plan" because it was used similarly by Miller, Galanter and Pribram (1960) and because it has similar connotations in psychological fields such as motor performance and problem solving. We by no means wish to suggest that plans are conscious, or consciously selected, though of course sometimes they are.

\section{Decision rules and measurement issues}

Two crucial questions about the plan/goal framework in Table 4 have not yet been addressed adequately:

(i) measurement: How can values $v_{j}$ and decision weights $w_{i j}$ be measured in practice?

(ii) decision rule: How are these measured values combined when selecting among plans?

Measurement For quantitative models of decision making, there are two different approaches to measurement of values or utilities $\left(v_{j}\right.$ or $\left.u_{i j}\right)$ and decision weights or subjective probabilities $\left(w_{i j}\right.$ or $\left.p_{j}\right)$. We refer to these two approaches as behavioral and psychophysical.

The behavioral approach follows the idea of revealed preference in economics: estimates of the desired quantities are inferred from an individual's choices. This approach has dominated theoretical research on measurement in relation to SEMAUT. For details and discussion, see 
Chapters 5 and 8 in Krantz, Luce, Suppes and Tversky (1971). It has sometimes been used, with limited success, to estimate utilities and subjective probabilities from laboratory or field observations. Tversky (1967) provided a paradigmatic example; a broad class of later examples focussed on marketing research is found in the use of "conjoint analysis" (Green \& Srinivasan, 1978; Gustafsson, Huber \& Hermann, 2001). The second approach emerges from the idea of "direct" judgment in psychophysics: the requisite quantities are obtained from an individual's numerical judgments or comparisons of intervals. Measurement theories for "direct" judgment of pairs (interpreted as intervals or ratios) are discussed in Chapter 4 of Krantz, et. al. (1971). comparisons or direct "ratio judgment We mention a few of the many examples of the use of psychophysical methods, mainly tied to the SEMAUT framework: Galanter (1962), Anderson and Shanteau (1970), Seaver, von Winterfeldt and Edwards (1978), Breault (1983), and Edwards and von Winterfeldt (1987).

The behavioral approach requires commitment to a decision rule, a law linking observed choices to underlying measured values. For SEMAUT, the decision rule is maximization of expected utility, as given at the bottom of Table 1 . The conditions under which $p_{j}$ and $u_{i j}$ can be consistently measured from observed choices are given in various axiomatizations, e.g., Savage (1954), Krantz, Luce, Suppes \& Tversky (1971), or Koebberling \& Wakker (2004a); methods of measurement are implicit in the various constructive proofs of uniqueness theorems for the expected-utility representation (Krantz, 1991).

A behavioral approach within the plan/goal framework would likewise depend on commitment to a decision rule, a specific linkage between the $v_{j}$ and $w_{i j}$ and the choice of a plan. Our discussion of question (ii), below, suggests that several different decision rules may be used in different contexts. It therefore seems premature (at least) to axiomatize behavioral measurement procedures based on a particular decision rule. Estimating $v_{j}$ and $w_{i j}$ based on psychophysical judgment, or, in the case of $w_{i j}$, based on the relationship between decision weights and probabilities previously established in the literature on prospect theory, is less problematic because it does not assume a decision rule; in fact, such numerical estimates could be used to test whether a particular decision rule is used in a given context.

Decision rules We now turn to question (ii), decision rules in the plan/goal framework. We noted above that a sum-of-products calculation, similar to SEMAUT, is just one of many combination laws for the $v_{j}$ and the $w_{i j}$ that could be considered in models of plan selection. Three seem particularly interesting: Tversky's additive difference model, majority voting by goals, and the class of conjunctive-choice models with thresholds.

We illustrate these three models using a highly simplified example of pairwise choice among insurance plans. Consider someone who is choosing among three plans, A, B, C, with three goals in mind: avoiding catastrophic loss; avoiding regret should a modest loss occur; and avoiding large premium payments. The three plans are shown as rows and the three goals are the columns in Table 5. The "decision weights" in the cells are just qualitative entries indicating how well a given plan satisfies a particular goal. Plan A guarantees protection against catastrophic loss through a high coverage limit. Plan B is the least expensive of the three plans. Plan C has a lower deductible than the other two plans, so modest losses will not lead to regret-little will be paid out of pocket.

Table 5 is structured so that for each pair of plans, there is a large, presumably salient difference with respect to one of the goals, but smaller and opposite differences with respect to the other two goals. For example, Plan B is much cheaper than A, but B has a coverage limit somewhat lower than A (less guarantee against catastrophic loss) and B has a deductible somewhat higher than A, so there is more chance of a modest loss that will lead to regret. 
Similarly, Plan C has a much lower deductible than B but is somewhat worse than B for the other two goals, and Plan A has a much higher coverage limit than $\mathrm{C}$ but is not as attractive with respect to the remaining goals.

Table 5: Goal conflict for three insurance plans

\begin{tabular}{c|ccc}
$\begin{array}{c}\text { Insurance } \\
\text { Plans }\end{array}$ & $\begin{array}{c}\text { Goals } \\
\text { avoid } \\
\text { catastrophic } \\
\text { loss }\end{array}$ & $\begin{array}{c}\text { avoid } \\
\text { regretting a } \\
\text { modest loss }\end{array}$ & $\begin{array}{c}\text { minimize } \\
\text { up-front } \\
\text { costs }\end{array}$ \\
\hline A & $\begin{array}{c}\text { excellent } \\
\text { (high limit) }\end{array}$ & OK & $\begin{array}{c}\text { poor } \\
\text { (expensive) }\end{array}$ \\
B & OK & $\begin{array}{c}\text { poor } \\
\text { (high deductible) }\end{array}$ & $\begin{array}{c}\text { excellent } \\
\text { (cheap) }\end{array}$ \\
C & $\begin{array}{c}\text { excellent } \\
\text { poor }\end{array}$ & OK \\
(low limit) & (low deductible) &
\end{tabular}

The first thing to note is that someone might decide between any two plans by counting the number of goals that are better satisfied by each of them. This is the majority-vote rule for pairwise choice, applied here to individual rather than social choice, with the individual's goals as "voters." This method may seem perfectly reasonable for any one pairwise choice, but in Table 5, it leads to the classic Condorcet/Arrow intransitivity, as depicted in Figure 1 (a). The figure shows that $A>B, B>C$, and $C>A$, each by two goals to one.

\section{INSERT FIGURE 1}

Alternatively, one might decide between two plans by evaluating the differences in the decision weights for each goal using a function that expands large differences relative to small ones, and then integrating across the goals by adding up the signed differences. This is a special case of the additive-difference theory of Tversky (1969). If the difference between excellent and $\mathrm{OK}$ is taken as one unit and that between $\mathrm{OK}$ and poor likewise is one unit, and if one cubes the differences (preserving sign), then the $\mathrm{A}, \mathrm{B}$ difference reverses: $B>A$, because the cost difference is worth $2^{3}=8$ units, while the regret and coverage differences are each only -1 . In fact, the whole intransitive cycle is reversed, as shown in Figure 1 (b).

There is strong evidence that, in multi-attribute situations, people tend to make withinattribute comparisons early and often (Payne, Bettman \& Johnson, 1993). This supports the idea that differences with respect to particular goals are evaluated first, and then integrated to make the choice. One might guess that vote-counts would often be used to integrate the multiple differences when decision making is deliberative and tradeoffs among different goals are difficult, whereas something like the Tversky mechanism would often be used where time is short and the decision maker looks for the most salient difference between two plans.

Finally, a threshold model is one that requires that one or more goals be satisfied to some minimum degree-the threshold is set with respect to the decision weight. An insurance purchaser who considered plans such as those depicted by Table 5 might first set a threshold of 
Figure 1: Two bases for intransitivity

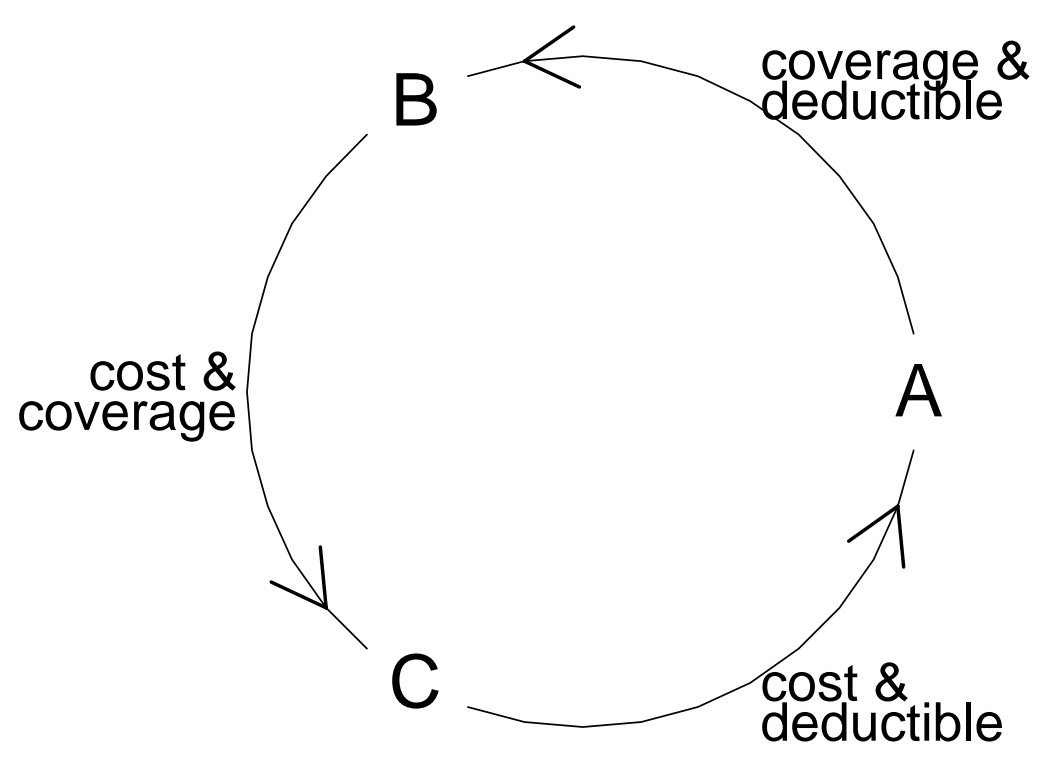

(a) Condorcet cycle

$$
\begin{gathered}
A>B \quad \& \quad B>C \& C>A \\
\text { each by } 2 \text { goals to } 1
\end{gathered}
$$

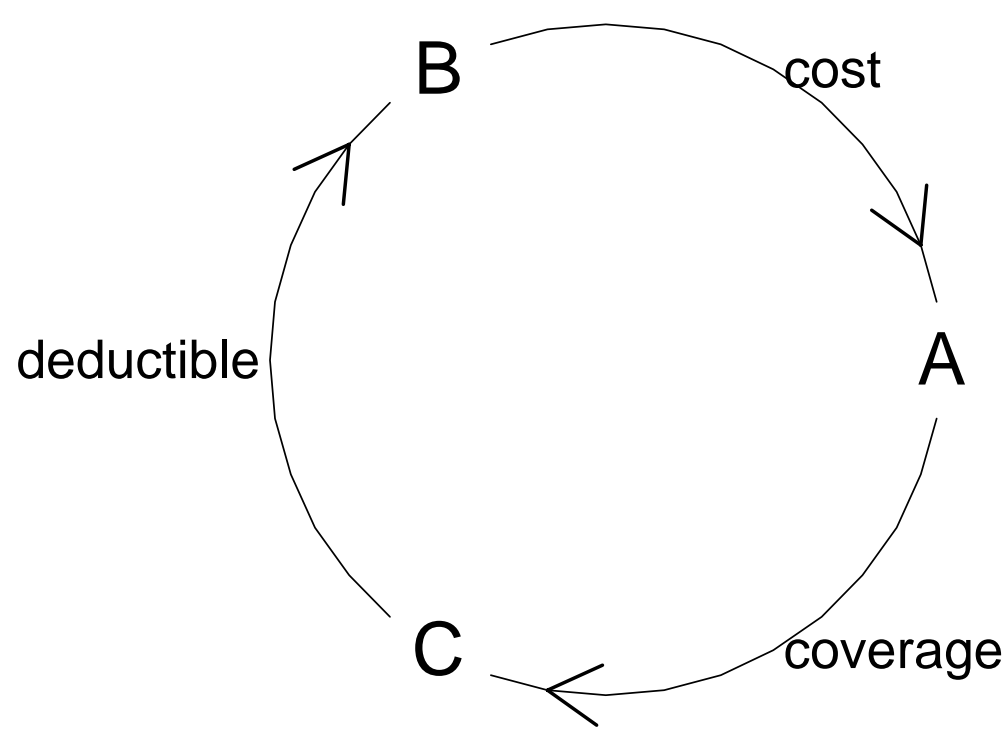

(b) Tversky cycle

$$
A<B \quad \& \quad B<C \& C<A
$$


"pretty likely" for the goal "avoid catastrophic loss." This decision-weight threshold for one goal would exclude plan $\mathrm{C}$ because of its low coverage limit. This would lead to an immediate decision in the case of two pairwise choices involving $\mathrm{C}$, and in a choice among all three plans, it would eliminate $\mathrm{C}$, leaving conflict between $\mathrm{A}$ and $\mathrm{B}$, which might be resolved in favor of $\mathrm{A}$ (two goals to one) or in favor of B (cost being salient). If, instead, the decision weight threshold for "avoid catastrophic loss" were set at "nearly certain" only plan A could be chosen. A decisionweight threshold could also be set for each of two goals, e.g., "pretty likely" to avoid catastrophic loss and also to avoid regret. This would eliminate plans B and C, leaving A as the only choice. A decision-weight threshold of "nearly certain" for both those goals would create severe conflict, since none of the plans available satisfy the criterion.

To describe behavior within the plan/goal framework, one must find out not about goals and decision weights, but about the decision mechanism. Prescriptive use of the plan/goal framework must consider the advantages and disadvantages in a given decision environment of various mechanisms that could be used to select a plan.

\section{Advantages of the plan/goal framework}

The overriding difference between the plan/goal and the SEMAUT framework lies in what questions are asked and answered most naturally.

A strategy/event layout focusses on the uncertain events that determine what outcomes will occur, given the choice of a particular strategy. Consideration of the decision-maker's goals is secondary. Consideration of multiple goals is inhibited, because it requires the evaluation of complex multi-attribute outcomes for each cell of the strategy/event matrix. A plan/goal layout focusses first on goals, and then, for each goal, on how likely or to what extent each strategy can achieve that goal.

Plans are generally selected to achieve multiple goals. Since it is easy to think about each goal, this principle is easy to apply: in analyzing decisions, one tries to encompass all the goals that might be under consideration, to ask which ones actually are considered and whether any important goals are not yet included. One also can ask probing questions about each goal: is it a product of the particular context? would the decision maker pursue the goal if the context made it less salient? and are some goals underweighted because of the context?

The plan/goal representation fits well with studies of insurance decisions. In Section 4 we use it as the basis for systematic discussion of the insurance anomalies surveyed in Section 1. Here, we give one example of how it might be applied.

People often purchase flood insurance after suffering damage in a flood, then many cancel their policies when several consecutive years pass with no flood (Kunreuther, Sanderson \& Vetschera, 1985). A simple explanation (Table 3) is that avoiding anxiety and feeling justified are both important goals. Following flood damage, anxiety is high, and reducing it is salient; it is also easy to justify buying the insurance, since a flood has just occurred. Thus, plan 1 is selected, based strongly on "feel justified" and "avoid anxiety." After several years, many people may find that the prospect of a flood no longer troubles their "peace of mind" so anxiety avoidance has low weight. Meanwhile, they do not feel justified in continuing to pay premiums and not collecting on their policy; the unfulfilled "feel justified" goal becomes more salient. The differential weighting of these two goals can lead to selection of the alternate plan. Note that this theory predicts that a decision maker who puts heavy weight on the goals of avoiding catastrophic costs and avoiding vast regret will likely continue to purchase flood insurance year after year, if the cost is modest.

A decision advisor, confronting such a view, might well ask the individual about the role 
played by feeling that insurance is unjustified, about the true importance of having a good justification, and about whether protection against catastrophic costs might be a good justification for paying the premium.

A laboratory study (Piao, Kunreuther \& Krantz, 2006) provides evidence that insurance decisions are affected by context and may be rendered suboptimal by salience. Subjects answered hypothetical questions about several types of protective decision, including purchasing insurance. One group was asked to state willingness to pay to eliminate a deductible, a second group to state willingness to pay for increased coverage limits, and a third subgroup chose between eliminating the deductible or increasing the coverage limit. For the first two subgroups, distributions of willingness to pay (for no deductible or for high coverage) were about equal; but in the choice situation, a strong majority chose high coverage rather than no deductible. These results suggest that people readily recognize the importance of insuring against catastrophe rather than purchasing a low deductible when comparing the two situations but otherwise may not consider the need to protect themselves against these types of events.

Apart from the present application to protective decision making, there are a number of other advantages of the plan/goal framework. Detailed discussion of these is beyond the scope of this paper, but we mention three here.

A decision is a choice among two or more plans. This idea is intended to build connections between decision sciences and other areas of cognitive science. It offers a connections to studies of planning, problem-solving, motor performance, automaticity, and consciousness. It suggests separate attention to issues of plan construction, plan selection, and feedback-guided execution of plans. In connection with the latter, it calls attention to cases of "going ballistic" - acting (possibly with feedback guidance) without further choice. Not everything can be chosen, but the presence of subordinate choice points, where subplans are considered or the current plan is reconsidered, can be an important feature of a plan.

Goals have intrinsic temporal markers. This principle can serve as the basis of a theory of intertemporal choice that frees temporal planning from the rigidity of a sequence of consumption periods, for which future consumption is discounted. A goal may be marked as very short term (getting out of the path of an oncoming truck), short term, medium term, etc. or in some cases on-going (maintaining good relations with a friend) or quasiperiodic.

Consideration of goals suggests a distinction between goals and resources. Some people want money (a goal); nearly everyone, however, wants to spend money (a resource) in the service of other goals. This leads to a consideration of multiple resources and to development of theories about commitment of resources to plans.

\section{Taxonomy of insurance-related goals.}

As a general framework for protective decision making, we assume that choice involves selection of a plan among several alternative options, that most plans are designed to achieve multiple goals, and that the set of goals to which a plan is directed may or may not be fully integrated into a single coherent mental representation with a clear evaluative component. Choice context (which includes the particular set of plans made explicitly available) affects which goals are considered, what value is placed on each goal, and how each plan is evaluated. Evaluation of a plan may take into account uncertainty about achieving various goals, the time at which different goals are likely to be achieved, who is likely to benefit in each case, and what resources are likely to be needed.

We now turn to a more systematic consideration of the different sorts of insurance-related 
goals by distinguishing between five main goal categories: sharing financial risk, getting return from an investment, feeling good (or at least not too bad), satisfying legal or other official requirements, and satisfying social and/or cognitive norms.

\section{(1) Financial protection by risk sharing}

Insurance can be provided to individuals at relatively low cost, for a negative event that has high financial impact, if the negative event in question has low probability, there are many at risk, and occurrences of the event are statistically independent. The benefit from one's premium payment is being protected against the risk of a large financial loss.

Some people may also hope for financial protection against negative events that have relatively high probabilities and relatively small financial impacts. Insuring against the loss of a contact lens is a well-known example. In this case, one does expect to make insurance claims and to get reimbursements: perhaps many times during a period of years. Such a goal might be predicated on the belief - usually, but not always erroneous - that total premium payments, over a period of years, will be less than total costs from the series of negative events. One believes, in effect, that the insurer will lose money in the long run. One might also hold this goal without such a belief, by simply neglecting probability considerations and focusing on the consequences if the event occurs. Failing to think about probability and believing that an insurer will lose in the long run, are usually cognitive errors. There is nothing paradoxical or uncommon about maintaining a goal on the basis of a wrong belief and/or an error in reasoning.

\section{(2) Benefits of investment}

Life insurance and annuity contracts sometimes combine financial protection for beneficiaries, in the event of death of the insured person, with various investment benefits such as capital accumulation and/or regularly received payments. Such contracts are attractive because people do have such investment goals. Health insurance contracts usually do not accumulate cash value or pay dividends, but often there are other regular financial benefits, such as free or low-cost annual checkups and discounts on prescription drugs.

The ability to be reimbursed, irregularly but frequently, for small losses may be perceived as a dividend stream coming from insurance contracts with low deductibles. The goal of getting some fairly regular returns can be distinguished from the goal of protection against small losses, discussed above. For the investment goal, one does not expect a net positive cash flow from the insurance; one merely expects some kind of cash-back return. In this sense, many individuals view one of the goals in purchasing an insurance policy as getting a financial return on their investment. Those who do not collect on their policies for several years period feel that their premiums have been wasted. It is hard to convince them that the best return on an insurance policy is no return at all.

Consider the case of flood insurance. As pointed out above, many individuals who are not required to have insurance cancel their coverage if they have not made a claim over the past several years (Kunreuther, Sanderson \& Vetschera, 1985). Such behavior would be understandable for people who revise the probability of a loss downward in the light of experience. Most people respond that the probability and the consequences of a similar event remain about the same as before and they are generally correct in this view. Furthermore flood insurance in the United States has mostly been highly subsidized on existing homes by the federal government so that the purchase of coverage has positive expected value in addition to protecting against catastrophic loss. We hypothesize that it is unpopular because it fails to provide cashback returns. 


\section{(3) Emotion-related goals}

There is a growing literature on on how affect and emotional goals impact on individuals decisions under risk (Loewenstein et al 2001; Finucane et al 2001). Three goals in this category are reduction of anxiety - "peace of mind", avoidance of anticipated regret and consolation.

We noted above that for low-probability, high-impact events, the benefit from one's premium payment is just being protected against the risk of a large financial loss. In addition individuals may purchase insurance to reduce their anxiety about experiencing such a financial loss. It is important to separate these two goals, financial protection against the loss and reduction of anxiety about the loss, because people vary in the degree to which each goal is important, and situations vary in the degree to which they make financial losses vivid and to which they provoke or relieve anxiety, and the relative importance of these goals may change over time. One may also anticipate anxiety, and take measures to avoid it (for example, some people claim that they do not fly in airplanes, not because they fear a crash, but because they fear being anxious about a crash). However, if one fails to avoid anxiety about a loss, there may still be opportunities to reduce the anxiety by taking protective measures, including insurance, where appropriate.

Regret is quite different from anxiety, in that it is primarily experienced after a loss occurs rather than before. Consider the example of mailing a package worth $\$ 50$. Insurance may be readily available. If one does not purchase it, then if the package is lost or badly damaged, one is quite likely to wish that one had purchased the insurance. Sometimes, the emotion of regret accompanying such a wish is quite unpleasant. If, at the time of mailing, one anticipates unpleasant regret if an uninsured loss occurs, then one may decide to avoid the possibility of such regret by purchasing the insurance.

Individuals may also purchase insurance as a form of consolation should they suffer a loss. In particular, if one has special affection for an item, such as a piece of art, then the knowledge that one can make a claim should the item by destroyed or stolen has special meaning to the person. Hsee and Kunreuther (2000) attribute the higher premiums for the same amount of coverage that individuals are willing to pay for objects they love than for those where they don't have special feeling as due to the need for consolation.

Usually, a strong positive attachment to an object either makes no difference to the probability of damage, theft, etc., or perhaps actually reduces this probability, if extra care is taken. Indeed, in a recent study of willingness to purchase warranties (Piao \& Kunreuther, 2006), "loving" an object made it seem less likely to subjects that the object would need repair. This was true whether or not statistical information about repair frequencies was given. This same study also showed that "love" did not, on average, produce a significant change in the anticipated cost of repair. If anything, anticipated cost decreases for a loved object. People should be less willing to purchase them for loved objects but, in fact, are more willing to do so.

\section{(4) Satisfying requirements}

Insurance coverage is often mandatory as in the case of automobile liability insurance required by states, homeowners insurance required by mortgage lenders, flood insurance in special flood hazard areas required as a condition for a federally insured mortgage, or malpractice insurance for several different professions.

In these cases, purchase of insurance may be viewed as a subgoal for meeting endgoals such as owning a car or a home or practicing one's profession. The same holds, to a large extent, when insurance decisions are made in conformity to social norms, rather than strict requirements. 


\section{(5) Satisfying social and/or cognitive norms}

Many insurance decisions are based on what other people are doing, or on what respected others think is an appropriate action to take. For example, a new parent may purchase life insurance mainly because his or her own parent, partner, or financial advisor thinks that it is important to provide protection for the spouse and child, and the amount purchased might follow some standard guideline (e.g., three times annual income). Once again, multiple goals may be in play: the new parent may be trying to achieve goal (1), protection of the family against a lowprobability high-impact event, but also may be trying to do what others expect or wish.

There is also empirical evidence that purchase of insurance, like adoption of new products, is based on knowledge of what friends and neighbors have done (Kunreuther, et al., 1978). There is a vast literature on social influence some of it especially relevant to protective decision making (e.g., Riad, Norris \& Ruback, 1999). For present purposes, however, we mainly want to distinguish between "non-extraneous" social influence-those actions and opinions of other people that provide useful information to a decision maker about the probability of a catastrophic event, about the likely consequences of such an event, or about the nature of insurance plans that could be advantageous - versus social influence that seems extraneous, in the sense used here.

A clear-cut demonstration of extraneous social influence would show mediated changes to select a particular plan involving insurance that was unaccompanied by changes in beliefs about the probabilities or consequences of a loss event. An illustration of this behavior came from a pretest interview of an earthquake questionnaire when a homeowner hearing that his neighbor had purchased earthquake insurance indicated that he would want to buy such coverage himself without obtaining any additional data on the risk he was facing or the actual cost of coverage (Kunreuther, 1978).

Numerous other examples can be cited. In our discussion of flood insurance (Table 4), we cited "feel justified" as a possibly important goal. Someone who purchases flood insurance soon after suffering damage from such a disaster may do so in part because it is easy to justify the expenditure, by pointing to the flood that just occurred. Cancellation of insurance coverage after some years of coverage may occur by using the social norm that it is hard to justify an expenditure that has not paid off.

In fact, people are concerned with justifying their decisions to themselves and others (Shafir, Simonson \& Tversky 1993). In the process, people often use arguments that have little to do with the tradeoffs between the cost of insurance and the expected loss that forms the bases of economic analyses of insurance transactions (Hogarth \& Kunreuther 1995).

\section{Explaining insurance decisions and anomalies}

We discuss SEMAUT, prospect theory, and the present model of constructed choice as potential explanations for insurance decisions and for what appear to be anomalies or suboptimal decisions. It will be obvious, from what has gone before, that one of our reasons for preferring the present model to SEMAUT has to do with the context-sensitivity of insurance decisions. We argue, however, that quite apart from this criticism, neither SEMAUT nor CPT comes close to describing the realities of insurance.

\section{The expected-utility account and its limitations}

We begin by considering the simple classical account of insurance decisions, based on a concave utility function for total assets. Since insurance contracts mostly have negative expected value, it is natural to account for the fact that people do purchase insurance by hypothesizing a 
risk-averse (concave) utility function $U(A)$, relating utility $U$ to total assets $A$. Such a concave function accords with the more qualitative concept of "catastrophic" loss. Compare a reduction in assets by loss $L$ or by loss ten time smaller, $L / 10$. For a concave curve, the drop in utility for loss $L$ is more than 10 times larger than the drop for loss $L / 10$. Thus, the decision maker prefers to make a premium payment $Q=L / 10$ rather than to accept a $10 \%$ chance of the loss $L$. More generally, the decision maker prefers to pay premium $Q$ rather than to accept a probability $p$ of loss $L$ if and only if

$$
U(A-Q)>p U(A-L)+(1-p) U(A) .
$$

We next give a concrete example, both to illustrate the reasoning given above and as an introduction to the limitations of this idea. Suppose that a decision maker has an exponential utility function for total assets, specifically:

$$
U(A)=1-e^{-A / A_{0}} .
$$

This utility function approaches an asymptote of 1 for very large $A$; the parameter $A_{0}$ gives the asset level for which utility difference from zero asset level is about $63.2 \%$ of the difference between zero assets and the saturated maximum utility level.

Note that $1 / A_{0}$ is usually thought of as the Arrow-Pratt measure of absolute risk aversion, i.e., it is curvature $-U^{\prime \prime} / U^{\prime}$ of the utility function. The exponential function is often used because it has the simple property that absolute risk aversion is independent of asset level $A$. Here, however, we find it more useful to interpret $A_{0}$ as a gauge of the magnitude of a loss $L$. To do this, we view zero assets as a natural reference point. An increment or decrement in assets of $A_{0}$, which spans over $60 \%$ of the utility range between zero assets and the utility asymptote can safely be classified as a large gain or loss. The usual (Arrow-Pratt) interpretation of $A_{0}$ is local: its inverse is the curvature of the utility function. By treating zero asset level as a natural reference point, we are able to give it this more global interpretation.

An example; the "loading" factor of an insurance contract Consider a household with total assets of $\$ 300,000$, including a home worth $\$ 200,000$, and suppose and that for this household, $A_{0}=\$ 100,000$. Suppose that the probability of a severe fire or natural disaster that would destroy their home is about 1/400 per year. By the preceding criterion, the loss of $\$ 200,000$ would be viewed as certainly a large loss for this household. Its expected annual loss, however, is $\$ 200000 / 400=\$ 500$. The household might be able to purchase insurance that would fully reimburse a $\$ 200000$ loss for about $\$ 1000$ annual premium: this would allow the insurer to pay claims, cover administrative costs, and make a profit. Because of the sharp curvature of the exponential utility curve, the household should be happy to pay $\$ 1000$ annually for this coverage; in fact, the maximum value of $Q$ that satisfies Inequality (1) is about $\$ 1585$.

This account of insurance seems plausible in the given example. However, it does not fare well when it comes to smaller losses. First, at the opposite extreme, it predicts unwillingness to pay much more than an actuarially fair price to eliminate deductibles. Suppose that the household under discussion has a 1/20 chance per year of fire or damage producing a loss of $\$ 1000$ or less. Their utility is nearly linear with money over a range of $\$ 1000$, and so the household should be willing to pay only a few cents more than the expected loss to eliminate a $\$ 1000$ deductible. In fact, the premium increases substantially to eliminate a $\$ 1000$ deductible, and many people are willing to pay it.

Even if one is willing to treat behavior vis-a-vis deductibles as an anomaly that the theory simply does not address, there remains the problem of insuring against intermediate losses. Consider the household in the above example, with a home worth only $\$ 100,000$. The expected annual loss is cut in half, to $\$ 250$, but willingness to pay for insurance drops by more than a factor 
of 3 , to less than $\$ 430$. If they can insure a $\$ 200,000$ home for $\$ 1000$, the premium for a $\$ 100,000$ home will be at least $\$ 500$; and so the theory predicts that they would prefer to be selfinsure for $\$ 100,000$ !

This is not a minor anomaly. Many types of insurance contracts have loading factors of 2.0 or more: the insurer charges at least twice the expected loss, to cover claims with a safety factor, to cover administrative costs and to make a profit. Homeowners insurance, even with a large deductible, generally has a loading factor more than 2. (For example, Sydnor, 2006 reports a loading factor of 2.6 in one western state for policies with $\$ 1000$ deductible, and much larger loading factors for decrements in the deductible.) The first example shows that for a loss of $2 A_{0}$, with probability $1 / 400$, the maximum acceptable loading factor for the household in question is $\$ 1585 / \$ 500=3.17$, a quite reasonable figure. But if the loss in question is only $A_{0}=\$ 100,000$, the maximum acceptable loading factor is $\$ 430 / \$ 250=1.72$, a value that might be difficult or impossible to find in the market for homeowner's insurance.

Maximum acceptable loading factor for a discrete loss $L$ One can solve Equations 1 and 2 for the maximum premium, $Q$, that a household is willing to pay, as a function of the loss $L$ and the probability $p$, and ask when the ratio $Q / p L$ is at least 2 . Figure 2 shows a contour plot of the maximum acceptable loading factor, $Q / p L$. Here $L$, the horizontal axis, is scaled in units of $A_{0}$. In the above example, 1 unit is $\$ 100,000$. The vertical axis is just probability, confined to the domain of reasonably low-probability events. What the figure shows dramatically is that acceptance of loading factors of 2 or more requires losses that are at least $1.4 A_{0}$ (increasing to 1.6 for higher loss probabilities). All the maximum acceptable loading factors exceed 1; thus, as we already knew, exponential utility leads everywhere to insurance seeking; but under this theory, realistic prices will be paid only for insuring losses that are large, on the scale of the $63.2 \%$ saturation constant. Since even wealthy people routinely insure possessions worth a few tens of thousands of dollars, accepting loading factors of 2 or more, the theory is contradicted widely by actual insurance behavior.

\section{INSERT FIGURE 2}

Similar calculations could be done for more realistic scenarios, in which there is a continuous probability distribution of losses rather than a discrete probability for a single known loss, and with alternative concave utility functions. Calculations with hyperbolic and power utility functions (for which the zero asset level is a very clear reference point) lead us to suspect that results similar to those in Figure 2 are fairly general.

Note that Figure 2 makes it easy to see why the exponential utility fails to account for decisions to have low or zero deductibles. In the extreme case, for a loading factor of 2 to be acceptable for eliminating a $\$ 100$ deductible, one must satisfy the equation $\$ 100 \approx 1.4 A_{0}$, thus, $A_{0} \approx \$ 70$. This means that the decision maker in question would prefer a sure $\$ 70$ over a $60 \%$ chance to win one billion dollars ${ }^{3}$.

In light of the fact that people do insure against small and intermediate losses, and in light of the discussion of insurance-related goals in Section 3 above, one may wish to modify the preceding simple theory by using the full strength of SEMAUT to incorporate multiple goals for insurance decisions, while retaining the core idea of a concave utility function for total assets. In Section 2, we suggested one reason why this might be difficult, or might lead to an unsatisfactory theory. Permanent goals with stable tradeoffs might indeed lend themselves to such a theory. Goals that depend strongly on what appears salient or goals that are suggested by the very

3. This argument is similar to that of Rabin (2000), which is set entirely in a frame of lotteries rather than insurance. 
Figure 2:

maximum acceptable loading factor for insurance

(exponential utility)

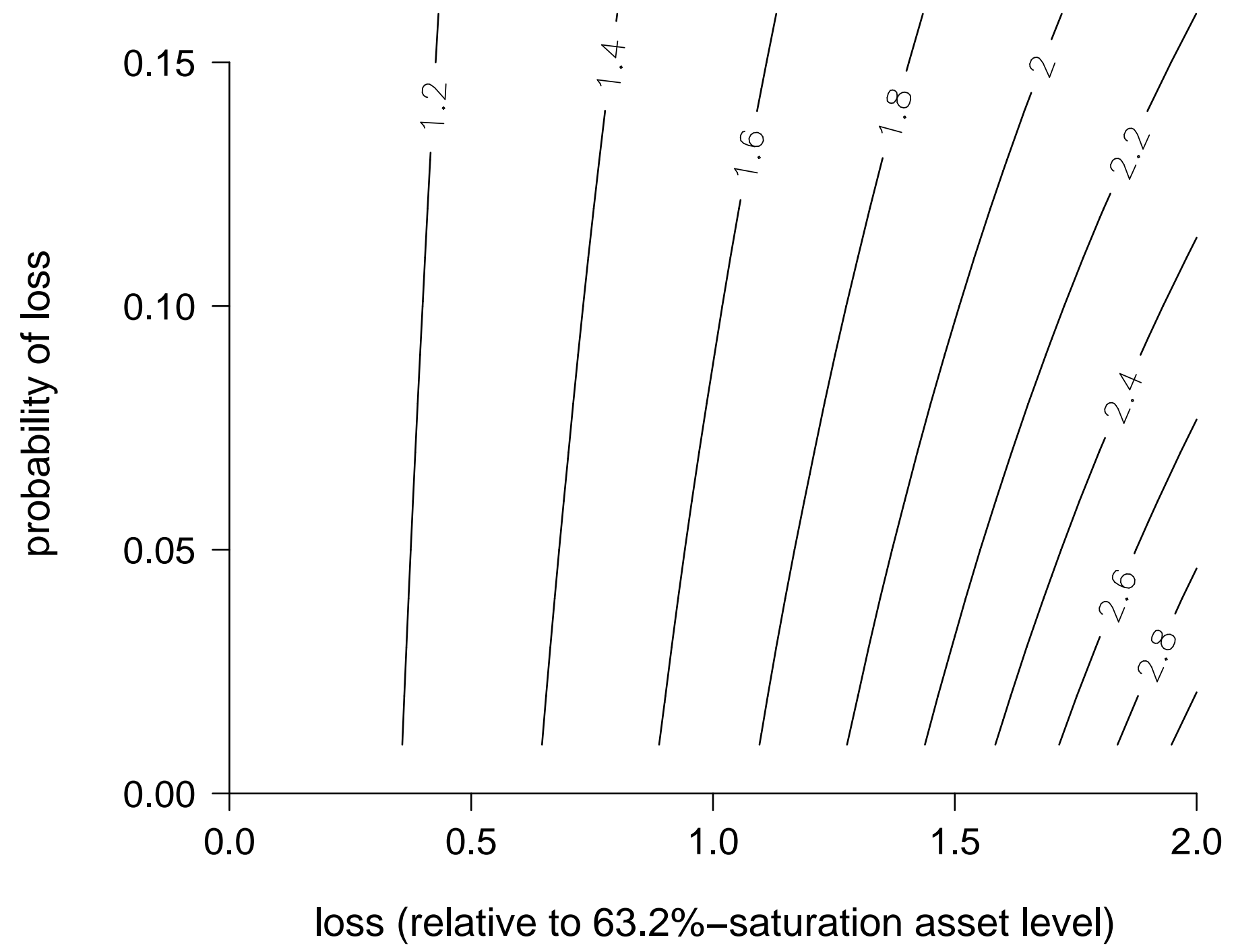


alternative plans among which the decision maker must choose could not be so incorporated.

In addition to the above argument based on context-dependence, there is another, based on reference-dependence, which provides a segue to discussing prospect theory. Many financial goals are perceived as deviations from the status quo, rather than as changes in total assets. The exponential utility function partially deals with this perception, since its prescribed choices among lotteries are invariant under translation (adding or subtracting a fixed constant $C$ to every asset level $A$ in the lottery). It can thus be interpreted in terms of increments and decrements from current asset level. However, even with an exponential utility curve, classical utility theory does not account for the difference between loss framing and gain framing for the same increments and decrements. For example, many owners of relatively new automobiles are happy to pay $\$ 40$ additional premium per year to have a small deductible, say $\$ 100$, on their collision insurance, rather than a $\$ 500$ deductible on an otherwise identical insurance contract. Yet the same owners would balk at paying $\$ 40$ for a lottery ticket that wins $\$ 400$ just in case their automobile happens to suffer appreciable collision damage during the coming 12 months. One would view such a lottery ticket as unlikely to win; moreover, the prize is not very large, even if one does win. So $\$ 40$ seems much too high a price. From the standpoint of utility theory, however, the lottery ticket is at least as valuable as the lower deductible on the insurance contract. The lottery ticket nets $\$ 400$ if there is appreciable collision damage. The insurance contract nets the full $\$ 400$ only if the damage exceeds $\$ 500$.

\section{Prospect theory and its limitations}

Characteristic features of prospect theory Prospect theory (Tversky \& Kahneman, 1979) was developed as a descriptive acount of risky choice. One important type of context effect - the effect of reference point-is accepted as an empirical fact and used as a starting point for the theory. Current assets serve as a reference point, relative to which losses are differentiated sharply from gains, and are valued quite differently. The theory replaces the concave utility function for total assets with a value function that has one branch for changes perceived as gains, another for perceived losses. Investigations of lotteries with known probabilities and gains or losses as outcomes led to a tentative specification of the general form of the value functionconcave for gains, but convex for losses - and to a general form for decision weights as a function of specified probability. Decision weights are applied as multipliers to the values that arise from gains and losses. For present purposes, the most important feature of the decision weight is that small probabilities, the ones most relevant for insurance contexts, are overweighted.

Cumulative prospect theory (CPT) was developed by Tversky and Kahneman (1992) for multi-outcome lotteries. It deals with the phenomenon of rank-dependence of the decision weights that are applied to particular gains or losses. This has become the standard form for the theory. For our simplified examples, where the insurance decision compares a sure loss of $Q$, the premium paid, with a chance $p$ to lose $L$ (otherwise nothing), the distinction is unimportant, but we continue to use the acronym CPT.

As a sidelight on CPT, one interpretation of rank dependence might be that multiple gains or losses are construed by the decision maker as defining a set of goals. For example, consider a lottery in which one wins $\$ 1000$ with probability $1 \%, \$ 50$ with probability $9 \%$, and otherwise (90\%) nothing is won or lost. The CPT value for this lottery can be written in the following form, where $V(x)$ is the value for gain $x$ and $W(p)$ is the decision-weight for probability $p$.

$$
V=[V(50)-V(0)] W(.10)+[V(1000)-V(50)] W(.01) \text {. }
$$

One can interpret this in terms of two goals: getting at least $\$ 50$, and getting $\$ 1000$ rather than $\$ 50$. The first term multiplies the value of the first goal $[V(50)-V(0)]$ by a decision 
weight based on the cumulative probability $(9 \%+1 \%)$ of achieving it, the second term similarly multiplies the incremental value of the second goal (given that the first has been achieved) by the decision weight for $1 \%$. This makes sense when goals are ordered, as they often are (e.g., getting at least a cost-of-living salary increase, then perhaps getting a large increase; at least not losing a chess game, then perhaps winning the game). It is this form of the equation that suggested the general sum-of-products decision rule for combining goal values with decision weights in Table 4 , i.e., $\sum v_{j} w_{i j}$, and thus led to the more general discussion of possible decision rules in a plan/goal framework.

CPT and insurance Explanations of insurance decisions based on CPT differ in a fundamental way from ones based on expected utility. The CPT value function is convex, not concave, in the loss domain - the opposite of what might be thought appropriate for explanation of insurance purchases with negative expected value for the purchaser. This shape is strongly supported by robust and oft-replicated laboratory findings that decision makers are risk-seeking, not risk-averse, in the domain of losses. The question arises as to how to reconcile two basic facts: people are risk-seeking with respect to losses, yet willing to insure against losses.

The usual CPT explanation of insurance purchase is based entirely on decision weights, rather than gains and losses: people manifest high decision weights to low-probability events. This means that they are willing to pay more than the expected loss for insurance.

This explanation has some intuitive psychological plausibility: people worry (sometimes excessively, sometimes not) about low-probability high-negative-impact events, and give them high weights in decision making. Within the standard parameterization of CPT (Tversky \& Kahneman, 1992) however, this explanation is not viable quantitatively. Corresponding to Inequality 1 , the CPT condition for paying premium $Q$ to insure against loss $L$ with probability $p$ is simply this:

$$
V(-Q)>W(p) V(-L) .
$$

Define the maximum acceptable loading factor as $\lambda=Q / p L$, where $Q$ is the maximum willingness to pay for the insurance. Substituting this into Equation 4 gives $V(-\lambda p L)=W(p) V(-L)$. In the standard parameterization of CPT, however, $V$ is a power function (of its absolute value, with sign restored), with exponent $\alpha$. This means that the factor $L^{\alpha}$ drops out of both sides of the above equation, giving a simple formula for $\lambda$ as a function of $p$ :

$$
\lambda=\frac{W(p)^{1 / \alpha}}{p} .
$$

Therefore the maximum acceptable loading factor is a function of loss probability only, independent of $L$. Whereas in Figure 2, for exponential utility, loading-factor contours are fairly vertical, i.e., they depend mostly on $L$ and only weakly on $p$, especially for low or intermediate losses relative to the saturation asset level, and for $p>1 / 100$. By contrast, in CPT the corresponding contours would be perfectly horizontal, depending only on $p$ and not at all on $L$. Consequently, rather than plotting loading-factor contours in $L, p$ coordinates, we simply plot loading factor as a function of $p$.

\section{INSERT FIGURE 3}

The solid (lower) curve in Figure 3 shows the plot of Equation 5, using the standard CPT parameterization of $W(p)$ for losses. The maximum acceptable loading factor is already below 2 for $p>2.6 \%$, and falls below 1 for $p>25 \%$. People with maximum loading factor below 1 
Figure 3: loading factors in cumulative prospect theory

(standard parameterization)

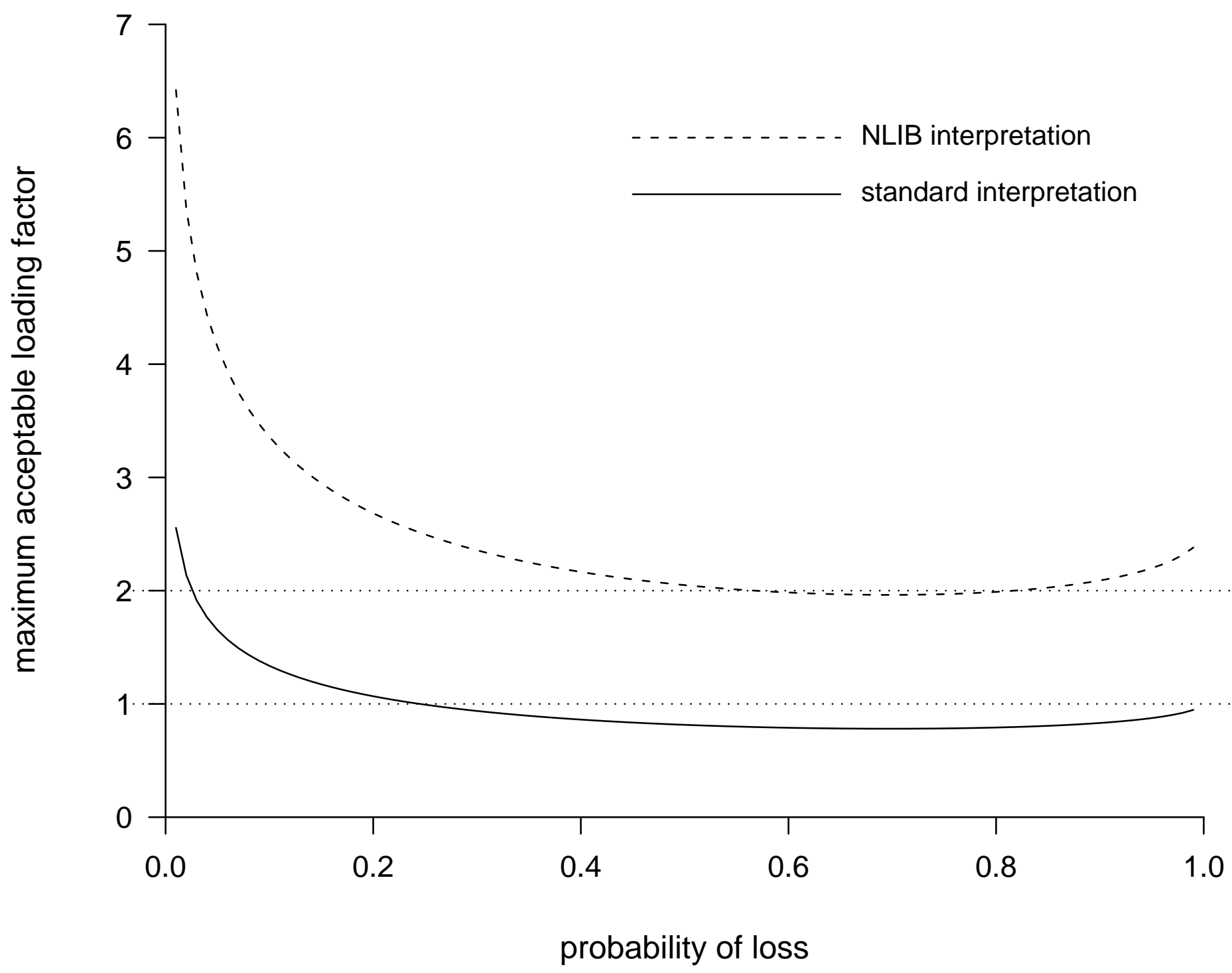


will not purchase insurance even when the transaction has a positive expected value.

The loading factors below 1 are perhaps not fatal for CPT: negative events with probability over $25 \%$ are unlikely to have high impact (or we would all be in sorry shape), and it may be both difficult and undesirable to insure against them. However, loss probabilities in the range between $3 \%$ and $10 \%$ are staples of insurance sales, mostly at loading factors above 2. Thus, CPT, in its usual form, simply cannot account for the market for insurance.

Figure 3 carries the calculation of loading factor down to a loss probability of 1/100; but in fact, another problem for CPT is that the probability weighting function derived from laboratory experiments cannot be extrapolated to very low probabilities, because at some point many people in effect round a low probability down to 0 , saying "this means it won't happen to me." Thus, CPT does not really deal with insurance against events with very low probability but very high negative impact.

An alternative interpretation Sydnor (2006) examined loading factors for deductibles in homeowner's insurance. He reached a similar conclusion: neither expected utility (where he focuses chiefly on the power, rather than the exponential form for the function $U$ ) nor CPT in its standard form can account for people's purchase of low deductibles. However, Sydnor suggested an important variant of CPT, according to which payments made for purchase (including premiums for purchase of insurance) are treated as negative gains, rather than as losses. This is the "NLIB" (no loss in buying) interpretation (Novemsky \& Kahneman, 2005). This assumption changes Equation (4): $V(-Q)$ is replaced by $-V(Q)$, i.e., losing $Q$ is replaced by losing the value that corresponds to a gain of $Q$. The equation becomes:

$$
-V(Q)>W(p) V(-L) \text {. }
$$

In the standard parameterization of CPT, the ratio $-V(Q) / V(-Q)$ is $1 / 2.25$, the inverse of the loss-aversion coefficient. The NLIB assumption therefore leads to the loading-factor equation

$$
\lambda=\frac{[2.25 W(p)]^{1 / \alpha}}{p} .
$$

This is shown as the dashed curve in Figure 3. Since $\alpha=0.88$ in the standard parameterization, the dashed curve is about 2.5 times higher than the solid curve. The loading factors given by this curve do not reject prospect theory out of hand as an account of insurance purchase. This is consistent with Sydnor's conclusion for deductibles on homeowner's insurance policies.

In short, Sydnor interprets willingness to purchase insurance as principally an effect of framing: though people are risk-seeking in the domain of losses, reframing a sure loss as payment of an insurance premium eliminates the loss-aversion factor for the premium, and then the remaining loss aversion (for potential losses covered by the policy) makes the insurance policy attractive. As Figure 3 shows, Sydnor's theory makes strong quantitative predictions about willingness to pay for insurance: the maximum loading factor should be independent of loss magnitude, and people should purchase insurance at loading factors of around 2.0 even for loss probabilities between $1 / 2$ and 1 . These predictions, which seem unlikely to be confirmed, could be tested more extensively in laboratory and field studies of acceptable insurance contracts.

Overweighting, underweighting and neglecting probabilities There is a more fundamental difficulty with the CPT account of insurance purchase. People considering insurance contracts rarely, if ever, have available explicit loss probabilities. Often, loss probability does not seem to play a role in their decisions (Camerer \& Kunreuther, 1989; Hogarth \& Kunreuther, 1995; Huber, Wider \& Huber, 1997). When loss probability is in fact considered, it is derived from experience, not from actuarial tables. However, Hertwig, Barron, Weber \& Erev (2004) showed that when the probabilities are based on experience, rather than on statistical summaries, 
people underweight low probabilities in making risky decisions except when there has been a very recent occurrence of the event class in question. Such underweighting could, of course, be one important factor in phenomena such as the cancellation of flood insurance policies that was noted above; it may not be easy to separate underweighting of the probability from difficulty in justifying the decision to continue the insurance and from fading anxiety. In any case, the overweighting postulated in CPT may not be relevant to most insurance decisions.

It seems implausible that people's willingness to pay for insurance is linked tightly to probability of loss and not at all to magnitude of loss. On the one hand, people often neglect probability in their thinking about insurance; on the other hand, people undoubtedly pay some attention to the affordability of losses. Insurance protection against very small losses, e.g., breakage of glassware in one's kitchen, would be viewed as absurd. The power-function formulation of the CPT value function leads to willingness to pay that is scale free, as shown in Equations 5 and $5^{\prime}$ above. This is one of the great conveniences in applying CPT-it does not matter whether the monetary amounts are dollars, Euros, or yen. But from the standpoint of insurance, it is a weakness. Losing 100 yen is much less serious than losing 100 dollars, and it is implausible that the loading factor for insurance will be exactly the same. In the domain of insurance, utility theory makes more sense psychologically, since it postulates that magnitude of loss does matter considerably. It would, of course, be possible to replace the CPT value function by a family of functions that do reflect the underlying scale of gains and losses. The family of functions could be constructed to be linear over some range of sufficiently small losses and gains, to be concave for gains and convex for intermediate losses, and finally, to have another concave region corresponding to catastrophic losses. for a given decision maker. Even such a function, however, would fail to account for insurance decisions that are based on multiple goals. In our view, a satisfactory understanding of insurance behavior needs to take into account the behavioral evidence that a number of different goals are sometimes considered in connection with insurance and other protective decisions. It is to this multiple-goal perspective that we now turn.

\section{Explanations based on constructed choice}

In the introduction we noted three classes of anomaly: (1) insuring against non-catastrophic losses, (2) underinsuring against truly catastrophic losses, and (3) exhibiting sensitivity to "extraneous" factors. In exemplifying these anomalies, we have already indicated several ways in which the theory partially explains behavior

Our classification of anomalies assumes that the main goal for insurance purchase is protection against catastrophic financial loss. Failure to pursue this goal, when it is readily attainable, and pursuit of other goals are viewed as anomalous. It is natural to explain these anomalies in terms of the alternative goals that people do in fact pursue, such as avoiding regret, reducing anxiety, getting a return on investment, or satisfying social norms, as suggested in our taxonomy in Section 3.

According to the plan/goal account, choices depend not only on goals, but on the decision rules used in plan selection. For example, the discussion of possible intransitivity with multiple goals (Figure 1) indicated how particular decision rules might increase the tendency to choose a low deductible and/or decrease the tendency to insure fully against a catastrophic loss.

\section{A process-oriented schema for constructed choice}

In the remainder of this section, we focus on some of the main cognitive processes involved in choice according to the plan/goal theory. To this end, Figure 4 offers a process-oriented schema for context-dependent constructed choice. The four dark arrows indicate some of the psychological functions essential to plan construction and plan selection, while the five dotted 
arrows indicate mechanisms of human perception or memory through which context influences plans, goals, resources and decision rules.

Central to the schema are goals and plans. The heavy downward arrow from goals to plans indicates the main way in which goals bear on plans: via decision weights $w_{i j}$. Psychologically, this arrow corresponds to the decision maker's beliefs about the likelihood of attaining goal $j$, or the degree of approximation to goal $j$, if plan $i$ is selected.

There is also an upward, dashed arrow from plans back to goals. This represents a feedback process, whereby a plan that is considered suggests additional goals that could be achieved through that plan, or, more generally, alters the importance values $v_{j}$ for the various goals. This feature was discussed at length following Table 4. As examples in which a goal is suggested or emphasized by a plan, we mentioned installing a protective device which one sees offered for sale in a catalog, or opting for an innovative provision available as an option in an insurance contract. We emphasize that this is not merely a question of a plan being attractive because it gives a high decision weight $w$ to an existing important goal. Rather, it is the value $v$ of the goal that is changed when it is made salient by the plan. In the extreme, the goal may have been unknown, in effect, $v=0$, prior to the decision maker's considering a particular plan.

The upward feedback arrow is one of five dashed arrows, each suggesting a different route by which context can affect constructed choice. We regard this feedback as a context effect because the plans initially presented constitute an important part of the choice context. In a fluid situation, where novel plans can be sought and constructed, the two arrows reciprocally linking goals and plans could be activated repeatedly.

The dashed arrow directly from context to goals represents another type of contextual influence. This arrow is labelled memory activation (Cantor \& Engle, 1993), because the context serves as a memory cue to activate concepts and thoughts related to particular goals. For example, if one recently regretted one's failure to purchase insurance, then thoughts about the possibility of a similar loss will remind one of that recent regret, and might thus strongly activate the goal of avoiding regret. Similarly, if one experienced anxiety because of lack of insurance, a contextual reminder of that anxiety might strongly activate the goal of avoiding future anxiety. More generally, most effects of context on emotion-related goals are tied to this arrow.

\section{INSERT FIGURE 4}

Context can also affect what plans are available and what decision rule is used to select a plan. These two dashed arrows in Figure 4 are labelled with another process in human memory, matching (Seifert, et al., 2002). Generally speaking, matching is linked to recognition: a present stimulus matches something stored in memory. Here, the matching process establishes a correspondence, or partial analogy, between the current choice context and some familiar situation. Finding such an analogy often leads the decision maker to recall the plan selected previously, and to select a partially analogous plan. Context thus adds to the set of plans under consideration. For example, if one has decided in one situation to self-insure (or not) against small losses, one may in a different but partly analogous situation seek an insurance plan with a high (or a low) deductible.

Alternatively or additionally, if there is severe conflict concerning the available plans, the decision maker may recall the method used previously to resolve the analogous conflict. Thus, context can make an additional decision rule available. This is most obvious in cases where analogy is used to support a complex decision rule, such as estimation and maximization of subjective expected utility, but context can also suggest simpler decision heuristics. For example, if one has previously simplified a decision problem by eliminating some of the available plans 
Figure 4. A schema for constructed choice dashed arrows show context effects

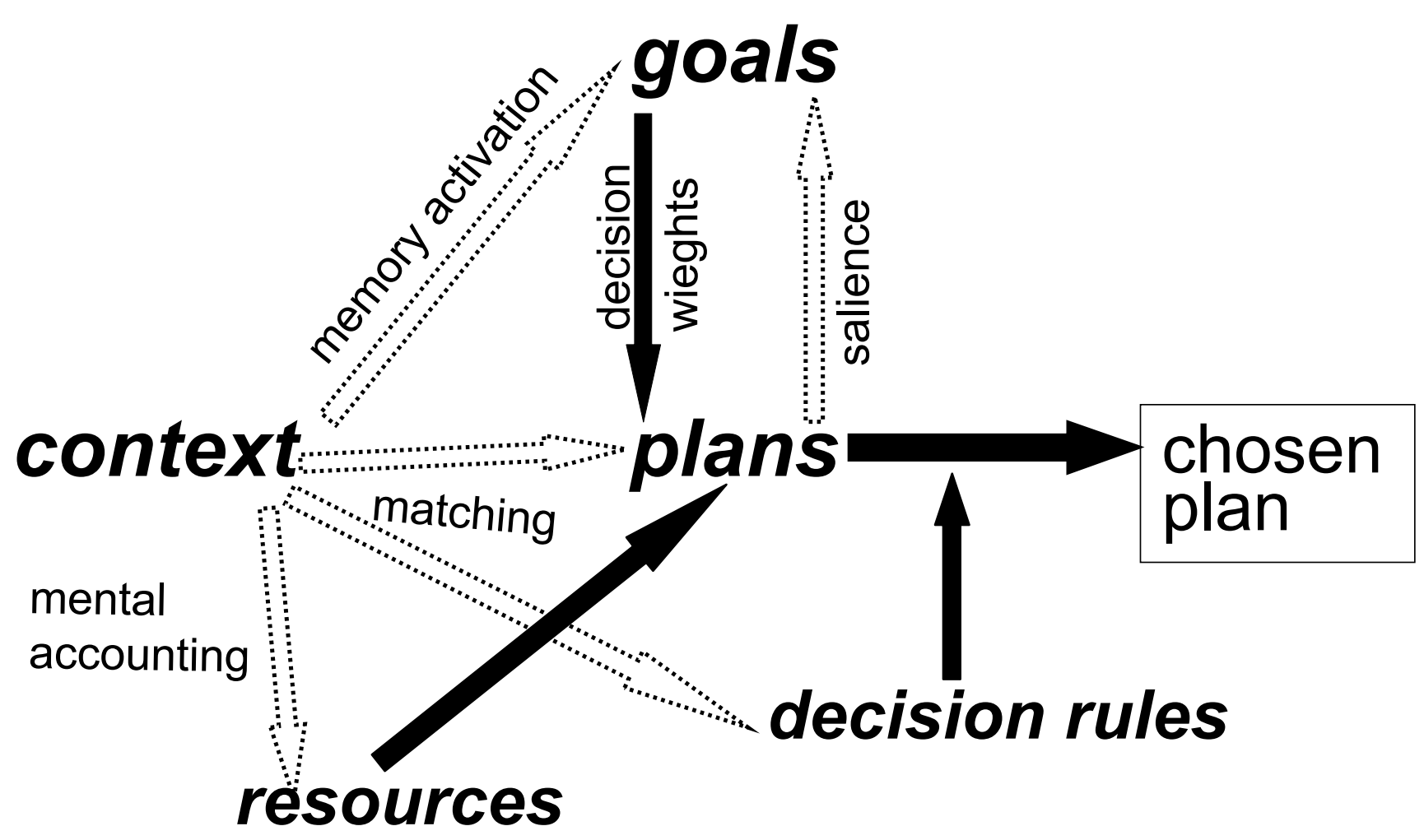


(e.g., by setting a threshold decision weight for an important goal), one may be led to attempt a similar simplification in the current choice situation.

The final dashed arrow in Figure 4 goes from context to resources. We label this by the psychological process mental accounting (Kahneman \& Tversky, 1984; Thaler, 1999). Changing the arrangement of mental accounts may either increase or decrease the resources available to solve a decision problem, and may thus suggest new plans or eliminate plans that draw on forbidden resources. Here is an illustrative anecdote. A couple planning a temporary partial move to a not-too-distant city was considering how to manage their two owned vehicles through the duration of this move. Each plan considered had severe disadvantages. In the context of a recent car rental, however, it occurred to them that in addition to their existing vehicles, money could be used as a resource to solve transportation problems. They could simply lease an additional vehicle in the new city. Although this solution involved additional expense, it seemed superior to previously considered plans. As long as their mental accounting only concerned management of existing vehicles, the better solution was unavailable; their insight was that money could be added to the resources called upon in planning.

Insurance decisions are often influenced by considerations related to resources. A person might choose not to pay a $\$ 150$ annual premium for general accident insurance (paying $\$ 500,000$ for loss of life in any accident involving a common carrier), but might pay $\$ 25$ for $\$ 500,000$ insurance on a single flight. The $\$ 150$ annual premium could be reframed temporally (less than $\$ 3 /$ week), or it could be framed as an expenditure within an insurance budget (find the needed $\$ 150$ by increasing the deductible on homeowners and/or automobile collision insurance), or yet alternatively, it could be framed as an expenditure within a general household budget (save $\$ 150$ by bring lunch from home every day for two months). Context (including advertising) determines how such an expenditure is framed.

Without going into great detail, we remark that under the plan/goal theory, mental accounting is not always "irrational." A decision rule that treats each of several goals as extremely important might well lead to selection of a plan that sets aside or otherwise designates resources devoted to each goal. Group decisions (by governments and other organizations) use explicit budgets as a resolution of goal conflict; individual decisions, with intra-individual goal conflict, may likewise be simplified greatly by such accounting, whether done mentally or through written budgets, dedicated savings, etc. Yet context can lead to redrawing the boundaries of such accounts.

Figure 4 provides a rich set of possible mechanisms that should be considered in a general theory of decision making and in particular are related to insurance anomalies. The first two classes of anomaly, insuring against non-catastrophic losses and underinsuring against truly catastrophic losses, relate directly to the multiple goals involved in selecting an insurance plan. Since goals can be made salient by plans, and salient goals may dominate the decision rule that is used to choose a plan, it is easy to see how marketing of insurance plans affects choices, and how the default settings for parameters within insurance plans also affect choices. Flight insurance is sold at airports, package insurance at post offices, credit-balance life and disability insurance is offered to credit-card applicants and bill-payers, dormitory theft insurance is offered to parents of college students, etc. In all these cases, the available insurance plans make salient one or more goals that might get little or no weight in a different context. Insurance plans also define temporal frames for planning (e.g., month, year, or lifetime), and thereby affect mental accounting and alter the perceived resources available.

The mechanisms shown in Figure 4 also help explicate some of the effects of "extraneous" factors on insurance decisions. Positive or negative affect attached to an object or event activates emotion-related goals. Thus, thinking about the possible loss of a loved object activates a goal of 
avoiding regret, and insurance may be perceived as reducing regret, even though the financial benefit of the insurance is no greater than in the case of an unloved (but needed) object. We have already discussed how recent experience of events such as flooding can also activate emotionrelated goals.

What friends and relatives advise or themselves decide to do is often extraneous, i.e., it does not change the set of plans available or expectations about probability or magnitude of loss. Adherence to quasi-legal or legal norms and to social norms. is itself an important goal, however, and may strongly influence the selection of a plan. Sometimes the decision rule itself may be no more complicated than adherence to a clear norm. One may purchase insurance (or not) simply because that is the expectation of one's boss or one's spouse. There are also important cases of formally mandated protection: examples include homeowners insurance, automobile liability insurance, and professional malpractice insurance, as well as fire-safety inspections, required fire drills, and seatbelt requirements. Large employers in the United States provide group health and life insurance. We also note the important role of defaults (which in many cases can be viewed as social norms) in affecting the details of chosen insurance plans. Being able to justify decisions is itself an important social norm; protective actions that other people select themselves define a norm, and in addition, doing the same is unlikely to be challenged or will be easy to justify.

\section{Novel prescriptive questions in constructed choice}

This approach to decision making raises a host of novel prescriptive questions. In SEMAUT, tastes are not challenged. If one wants an extraordinary wine, one can pay $\$ 500$ per bottle. Similarly, to promote peace of mind, one can pay $\$ 80$, reducing a deductible from $\$ 500$ to $\$ 250$ even though over a 10 year period, one will spend $\$ 800$, while the probability of collecting the extra $\$ 250$ at least once within 10 years is only about 35\%. In the original loss/gain framing demonstration of Tversky and Kahneman (1979), the intent was purely descriptive: gain framing produces risk aversion, while loss framing, for logically equivalent outcomes, leads to selection of the risky plan. There is no guidance about which frame, if either, should be used. Advice about the right choice would presumably be given on an entirely different basis, maximization of expected utility. In the constructed choice framework, however, the "true" preferences that lead to maximization are mythical: all choices are context-dependent. In the absence of other prescriptive guidance, one is forced to consider whether a given problem should be framed in terms of loss or gain.

In what follows, we discuss in greater detail the two features of our theory that are especially important for understanding insurance anomalies. The fact that plans available in the decision context can suggest new goals leads to insights about insuring against non-catastrophic losses and about sensitivity to extraneous factors. We mention several additional examples. The idea of decision mechanisms involving decision-weight thresholds for important goals helps us to understand failures to insure against truly catastrophic losses.

\section{Goals suggested by plans}

The very idea of risk sharing through insurance was once a novel family of plans. Prior to its invention, some severe financial risks (especially in trading over long distances) would have seemed unavoidable. The advent of insurance plans would have led many to adopt the goal of reducing financial risk, just as the availability of seat belts, and later of air bags led many to install them. The availability of these innovations led to people's adopting the goal of reducing their risk of death from automobile accidents. At a later time, both became mandatory. Indeed, the fact that people adopt new goals in response to novel plans is probably one of the principal forces underlying technological and social change. 
In the realm of health insurance deductibles, a rather important goal comes into play: one might wish to avoid being placed in a future position where one can reduce out-of-pocket costs by accepting increased health risks for oneself or one's family, e.g., by declining preventive care or other advisable but optional treatment. Avoiding such difficult tradeoffs is made salient by the availability of health-insurance plans that pay for routine and preventive care. If the available health plans included only hospitalization and major medical expenses, then people would continually make health-care/money tradeoffs. They might very well wish they didn't have to do so; but if people were accustomed to making these tradeoffs, many would be reluctant to pay large up-front premiums to gain coverage for routine and preventive care. This also illustrates how plans affect temporal framing: full-coverage plans place health-care decisions in a fairly long-term frame, envisaging repeated use of the health-care system, and thus make more salient the goal of avoiding repeated difficult tradeoffs.

Though one can give many additional positive examples of important goals that are adopted in response to novel plans, it is also clear that marketers can take advantage of human goal malleability to generate plans that are deceptively attractive to consumers and highly profitable for the marketers. One broad area where this can occur is in setting default values for plans.

A dramatic example of the effect of defaults was uncovered with the introduction of nofault automobile insurance in New Jersey and Pennsylvania. Both states introduced the option of a reduced right to sue accompanied by lower insurance rates. In New Jersey individuals had to acquire the right to sue and in Pennsylvania the default was the full right to sue. When offered the choice, only about 20 percent of New Jersey drivers chose to acquire the full right to sue while approximately $75 \%$ of Pennsylvania drivers retained this right. In other words residents in both states maintained the default option. This finding was confirmed in a laboratory experiment where subjects (Johnson, et al. 1993) were given a similar choice, but were randomly assigned to one of three groups: current automobile insurance with full right to sue, with limited right to sue, or with no information about current right to sue.

The overacceptance of default values has become a well-known and much studied phenomenon, and probably is caused by several different underlying mechanisms. Among these, we believe, is the influence of the default on people's actual goals. Many more New Jersey than Pennsylvania motorists may have thought that they would actually like to sue, since that option was endorsed as a norm by the default plan they encountered. More generally, defaults may be viewed by consumers as goal-setting norms, when in fact, they are often the most profitable option for a vendor and thus possibly the least favorable for the consumer.

Insurance plans that bring in high profits to insurers, in part by suggesting goals that might otherwise not be adopted, include low deductibles, so-called disappearing deductibles, rebate plans, credit-card insurance, flight insurance, and insurance on packages sent through the mail.

Low deductibles were discussed above. Disappearing deductibles are plans for which the deductible applies in the case of small and moderate losses, but not for large losses. This may suggest the goal of avoiding an out-of-pocket payout in a situation where one is already dealing with the hassles of a major loss. This sounds attractive; but, in fact, loading factors are high: the probability of major loss is low, the additional amount reimbursed by the insurer with a major loss is not very high (only the deductible), and so the average return to the insurance purchasers is much less than the additional premium paid.

Rebate plans return a portion of the insurance premium, provided that no claim has been made in a specified period of time. These plans may lead consumers to adopt the goal of getting an "investment return" on their insurance premiums. A number of years ago, an insurance company introduced a disability insurance plan for which policyholders received at age 65 a full rebate of all the premiums paid to that date, provided that no claim had been made. This 
promised an attractive return, but it created an economic incentive for those approaching the age of 65 to avoid making a claim, if they had never made on up to that point. People who were likely to need disability payments found themselves not wanting to use their policies. This "reverse moral hazard" led regulators to request that the company withdraw this plan from the market, since it undermined the main goal of insurance: those who suffer an insured loss should be able to collect the amounts for which they are covered.

Credit-card insurance and flight insurance are egregious examples of plans that suggests goals in a particular context and exhibit very high loading factors. In each case, the suggested goals can be achieved much less expensively. Flight insurance was discussed in our introduction. The cost of this insurance is 4 to 8 times higher than for the same level of coverage with general accident insurance, and the latter covers many additional risks for a much longer period of time. Credit-card insurance is essentially life-and-disability insurance, covering only the amount of one's credit card debt. Its selling point is that the current credit-card balance would be paid off in case of death or disability. For people whose credit-card balances are burdensome, this would have been an attractive goal. Unlike the usual life and disability policies, the premiums for such insurance plans do not take age into account. For a person not at high risk, or who is already adequately protected by life insurance and disability insurance, adopting the goal of paying off a credit-card balance in this way seems unwise: the risk is not catastrophic, and with premiums in the neighborhood of $\$ 2$ per $\$ 100$ insured, the loading factor is high. We do not know who actually does purchase this insurance. If it is mostly purchased by people at high risk, then the average loading factor may be reasonable.

As a final example, consider insurance on packages sent through the mail. Within the U.S., current rates are slightly over $\$ 1$ per $\$ 100$ of insured value (more for insured value less than $\$ 200$, and up to a maximum of only \$500). While we don't know the probability of loss or damage, experience suggests that it is far less than $1 \%$. The loading factor is high, and the losses involved are seldom catastrophic. However, people generally do what they can to protect objects sent through the mail; for example, they may take care in preparing the package. An insurance plan may be viewed as offering an additional opportunity to take care.

\section{Thresholds for decision weights}

Above, we discussed plan selection mechanisms involving thresholds for the decision weights pertaining to a set of important goals. We suspect that this is one of the most frequently used mechanisms. It is observable when group decisions are made in public: several goals are discussed, and the plan finally adopted is one that offers a good chance to achieve each of them. A plan for a new bridge is selected because the decision makers believe that the construction cost will be within the budget limit, that the bridge will handle the expected volume of traffic, that it will be safe, and that it will have a long lifetime with acceptable maintenance costs. Other goals (e.g., aesthetic quality) may also be considered and traded off against additional costs, but the four goals just listed are essential, and the likelihood of achieving each must be high. One may ask, how high? Certainty is not achievable for any of the goals. Most likely the threshold for acceptance will be set very high for safety and less high for the other goals.

When it comes to protective decisions, low probabilities of negative events may fall within acceptance thresholds. Table 3 provides a simple example. Someone may regard the avoidance of catastrophic loss as an essential goal, yet the probability of 0.98 of achieving that goal may be high enough to satisfy this person's acceptance threshold-in which case plan 2, no insurance, may be selected.

In fact, failures to purchase flood or earthquake insurance are very common. Individuals know that floods and earthquakes occur, but they "do not think it will happen to them." This can 
be viewed as underweighting low probabilities, consistent with Hertwig, et al. (2004); we take the slightly different theoretical view that the mechanism is one of acceptance thresholds for plan selection. Theories that postulate over- or underweighting of low probabilities have to commit to one or the other, for any given probability level and a given type of evidence bearing on the probability. Our threshold theory, by contrast, suggests that the threshold level in a decision rule depends on the importance of the particular goal, on the importance of other competing goals, and quite possibly on other factors, especially on social norms concerning acceptable levels of risk. Thus, a given risk of failure to achieve the goal may appear to be underestimated (as in the example above, where a $2 / 100$ chance of severe flood is neglected) or the same probability may appear to be overestimated (e.g., where a social norm demands near certainty for a particular goal).

In the case of floods and earthquakes, these acceptance thresholds may well be too low: the events can be catastrophic for uninsured victims. These cases are complex, however, because of private insurers are reluctant to enter the market (regionally correlated losses lead to high levels of risk to the insurer), premiums are high, and people count on government intervention as a form of insurance. What is clearly needed in these cases is a norm that leads people to purchase insurance. This could take the form of a social norm within a group or the form of a legal requirement to insure. Legal mandates, other official norms, and social norms all play a role in getting people to protect themselves adequately, as noted above.

\section{Prescriptive implications}

In standard economic analysis, consumer tastes go unchallenged. It is not irrational to pay $\$ 500$ for an extraordinary bottle of wine that cannot be purchased for less. Paying $\$ 80$ for a feeling of "peace of mind" likewise should go unchallenged. In a constructed choice framework, however, these are not literal tastes, comparable to liking raspberries or disliking prunes, they are constructed choices; it is the construction process that can be examined critically.

Suppose, for example, that "peace of mind" is obtained by paying $\$ 80$ to reduce the deductible on homeowner's insurance from $\$ 500$ to $\$ 250$, and that the purchaser also believes (rather accurately) that she, and others in comparable situations average only about 1 claim every 25 years that exceeds $\$ 250$. If she thinks about a commitment to 10 years of insurance-withpeace-of-mind, this will cost $\$ 800$ extra over that period of time. The chance that she will collect the extra $\$ 250$ at least 3 times in the 10 years (thus breaking about even) is about 1 in 100,000. Alternatively, she can think about the commitment in terms of cost per week: less than $\$ 2$ for peace of mind. Her choice may very well change, depending on whether she thinks about the cost for peace of mind in a weekly, annual, or ten-year frame. In the weekly frame, $\$ 2$ seems trivial and $\$ 250$ looms large (despite its low probability). In the ten-year frame, $\$ 800$ looms large and the prospect of a $\$ 250$ loss does not have so much effect on peace of mind.

The constructed-choice framework in fact leads to a host of difficult prescriptive questions. We provide a sampler of questions (but note that most of the answers are beyond the scope of this paper and should be addressed by future research). What is the right temporal framing? What about framing as gains versus losses? What is the best way to keep mental accounts, i.e., what resources should be committed to important goals and what should remain fungible? What decision-weight thresholds should be set on various goals? Are there intrinsically maladaptive configurations of goals? When should one use social norms as a guide? When should one pursue emotion-related goals, versus attempting to manipulate and control one's emotions?

Rather than tackling these questions, we limit our prescriptive remarks to three short subsections. The first concerns financial benchmarks for insurance, the second discusses 
emotion-related goals, and the third sketches a program of consumer education. Our rationale for these choices will be embedded in the respective subsections.

\section{Financial benchmarks}

Financial benchmarks are useful as starting points for critical analysis of constructed choices. For example, the preceding example, in which someone pays $\$ 80$ per year extra to decrease a homeowner's deductible from $\$ 500$ to $\$ 250$ would raise a warning flag, because we think that in the world of insurance contracts, higher deductibles are almost always better deals. More generally, any violation of one of the benchmarks we will propose here deserves careful analysis.

The three simple benchmarks we suggest all run counter to popular choice. The reason is simple: since popular choices are popular, insurers can collect higher premiums for them. Unpopular choices can offer excellent protection from financial risk at reasonable cost.

1. Consider the maximum loss and its probability What is the maximum loss one could suffer from a particular type of negative event, how likely is such a loss, and how much would it cost to insure fully against it? A person earning $\$ 60,000$ per year probably does not need $\$ 1$ million life insurance, but $\$ 300,000$ would give that person's beneficiaries five years to adjust to the loss of income. The probability of death in the next year, from all causes, is never negligible, so that much insurance should be purchased, if one can find the money for the premium. Similarly, homeowner's insurance should, if at all possible, cover the full replacement value of one's house at least in case of fire, since the probability of total destruction by fire is not negligible.

2. Look for the highest deductible To opt for a high deductible means that one is selfinsuring against losses smaller than that amount. One is thereby saving money on insurance. Of course, the deductible must be set low enough so that one can handle the loss if it occurs. Again, a person earning $\$ 60,000$ per year may not be able to accept a $\$ 10,000$ deductible, but a $\$ 2000$ loss, although very painful, might be manageable. Avoiding the possibility of any pain can be expensive when converted to the extra annual premiums one must pay to achieve this goal.

To illustrate the operation of these two benchmarks, consider the following three homeowner's insurance policies:

$\begin{array}{lrrr} & \text { annual premium } & \text { deductible } & \text { coverage limit } \\ \text { policy A } & \$ 600 & \$ 1000 & \$ 100,000 \\ \text { policy B } & \$ 750 & \$ 500 & \$ 100,000 \\ \text { policy C } & \$ 750 & \$ 1000 & \$ 150,000\end{array}$

Assuming that the individual can manage a loss of $\$ 1000$, policy $\mathrm{A}$ is superior to $\mathrm{B}$ : the reduction from $\$ 1000$ to $\$ 500$ deductible is not worth $\$ 150$. Assuming that the home would cost $\$ 150,000$ to replace, policy $\mathrm{C}$ achieves much more important goals than B. Someone who purchased B and whose home was destroyed by fire would be $\$ 50,000$ short of the funds needed to rebuild. The comparison of $\mathrm{A}$ with $\mathrm{C}$ is a bit less clear. If the loading factor for the extra coverage is about 2.0, then the extra $\$ 150$ premium implies a probability of $\$ 75 / \$ 50000=.0015$ per year for a total loss by fire. If more than 1 in 1000 homes of this type, in this region, are lost to fire each year, then $\$ 150$ extra would be well spent on maintaining the needed coverage. 
3. Avoid policies with rebates or other return of premium Consider the following two policies for disability insurance:

$\begin{array}{lrrr} & \text { annual premium } & \text { deductible } & \text { rebate } \\ \text { policy A } & \$ 1000 & \$ 600 & \$ 0 \\ \text { policy B } & \$ 1600 & \$ 0 & \$ 600\end{array}$

Policy A dominates policy B financially: it costs $\$ 600$ less, and B only provides the rebate in case the individual makes no claim during the given period. (Meanwhile, the holder of A can earn interest on the $\$ 600$ that he or she has saved.) Yet, when the choice between these two policies was given to a set of subjects in an experiment (Johnson, et al., 1993), a majority chose B over A. Presumably many of these subjects adopted a goal of maximizing the chance that they would get a return on their insurance investment.

As noted in the preceding section, there is another reason for avoiding Policy B: the insured person may decide not to make a justified claim in order to obtain the rebate. This is a form of reverse moral hazard for insurance. It defeats the main goal of the insurance.

\section{Emotion-related goals}

Emotion-related goals may lead to purchasing financially unattractive insurance policies. Hsee and Kunreuther (2000) tested the following scenario:

You are shipping two vases you purchased for $\$ 200$ each to your home. Suppose that the two vases will be packed in the same box so that if one vase is damaged, the other is also damaged, and if one is not damaged, the other is also not damaged. Of the two vases, you love one much more than the other. You feel that the vase you love is worth $\$ 800$ to you and the other one is worth only $\$ 200$ to you. Suppose you have the opportunity to purchase shipping insurance and that you have enough money to insure only one vase. Which one of the two polices will you purchase?

Policy A: The insurance premium for the vase you love is $\$ 12$.

Policy B: The insurance premium for the vase you don't love as much is $\$ 10$.

The decision maker should choose Policy B, because it costs only $\$ 10$, yet offers exactly the same financial benefit as Policy A. When subjects were asked to make the choices between the two policies $63.5 \%$ of the respondents chose Policy A. Presumably policy A evoked a goal of being consoled somewhat for the loss of the vase that was loved, or the goal of showing how much one cares about the loved vase.

Of course, this is a contrived situation, in which there is no real benefit, emotional or otherwise, to paying $\$ 2$ extra for the insurance. The more general point is that attachment to objects, and other sorts of emotional goals, should raise a flag for consideration as to how important the goals are and what one is really getting from the insurance, in the same way that violation of the financial benchmarks raises a flag.

There are certainly situations where an individual should be willing to violate financial benchmarks to satisfy important emotional goals. Consider the following example. A couple is renting a car for a vacation trip and is asked by the rental company whether they want to pay $\$ 2$ extra per day to avoid paying up to $\$ 1000$ if they should have an accident. The couple can manage the payment of $\$ 1000$ if necessary, and the chance of an accident happening on any one day is much less than $1 / 500$, so paying the $\$ 2$ has negative expected value. According to the 
second financial benchmark, they should take the $\$ 1000$ deductible and save $\$ 2$ per day. Suppose, however, that the person arranging for the contract is unable to convince her spouse of the benefits of following this rule: he will worry much less if they pay the $\$ 2$ per day for full coverage. She will probably conclude that $\$ 2$ per day is a small price to maintain peace of mind for her husband and harmony on the vacation.

\section{Consumer education}

What should be the outlines of a program of consumer education for insurance? Based on the model of constructed choice that we have developed in this paper, the most appropriate instructional strategy would focus on the goals that underly consumers' choices and would highlight features of desirable insurance plans that can achieve those goals that matter most to each person.

\section{Extend the frame}

It seems useful to present competing plans in multiple frames. The most obvious framing is temporal: a small deductible that generates peace of mind at what seems like a low price for one year looks much worse, as noted above, when the expense is added up over ten years. Probability of loss is also easier to understand in a longer time frame: a probability of $4 \%$ per year translates into about a 1 in 3 chance of having one or more losses in 10 years, i.e., a 2/3 chance of no loss at all. Extended temporal framing also has the effect of putting the loss in a long-run perspective. Paying $\$ 1000$ out of pocket is very painful for most people, but may seem more manageable if it happens only once in 10 or 20 years.

Apart from temporal framing, it may make sense to broaden the frame of any single insurance decision to include other protective needs. A financially unfavorable choice in one domain, multiplied by 3 or 4 different domains, can seem obviously wrong.

The goal of return on investment may be more resistant to broadening the frame temporally or for other needs, since the return is also multiplied. Thus, insurance needs to be framed alongside other investments. Paying $\$ 600$ extra for a rebate policy, which may or may not bring a return of $\$ 600$, seems obviously inferior to investing the $\$ 600$ in a certificate of deposit or in mutual funds. Such reframing is of course only meaningful for those who perceive other investment opportunities as accessible.

\section{Provide economic incentives}

The most obvious economic incentive that could be provided to an individual is a rebate check: imagine that the person is contacted by his insurance agent, after having purchased a policy with a low deductible, and urged to increase it to a higher one. The agent could indicate to him that he would save $\$ 100$ by converting his policy from a $\$ 500$ deductible to $\$ 1000$, and would be mailed a check for $\$ 100$ if he decided to do so.

This scenario is of course predicated on the constructive involvement of insurers and agents in consumer education.

\section{Address emotional concerns}

Individuals are likely to buy insurance in order to meet emotion-related goals, such as achieving peace of mind, avoiding regret, or gaining consolation in case of a loss. One may hope to point out paths by which they can still meet some of these goals through insurance plans that are more attractive financially. In the example given above under emotion-related goals, it may not be difficult to convince a person who was willing to pay $\$ 12$ for an insurance policy on a vase 
that he loved that he would still be able to gain consolation by only paying $\$ 10$ to insure the vase he didn't love, since the claim would be based on both vases being destroyed simultaneously. The fact that the person didn't purchase a policy on the vase he loved would be irrelevant for obtaining compensation and hence consolation.

It may also be necessary to challenge emotion-related goals. Wanting to avoid regret is understandable; but once the individual sees clearly that this is what he is doing, he may think it is not worth the extra money.

\section{Provide instructional material}

Understanding and use of probabilistic concepts is a modern development in human reasoning, and is attained only through some combination of formal instruction, casual learning, and apprenticeship experiences. Nisbett, Krantz, Jepson and Kunda (1983) introduced the concept of statistical heuristics: short-cut guides to reasoning that incorporate some probabilistic concepts and lead to their use in everyday reasoning. Fong, Krantz and Nisbett (1986) showed substantial temporary improvements in everyday probabilistic reasoning from suitably designed instructional modules. Protective decision making could similarly benefit from instruction. In fact, individuals can be aided in their understanding of the functions of insurance by instructional material (Piao, Krantz \& Kunreuther, 2006).

More specifically, one way to convince people of the importance of Financial benchmark 1 is to provide graphic examples of the importance of having protection against a catastrophic loss rather than a small loss. A homeowner would be more likely to purchase a policy with coverage of $\$ 150,000$ and a $\$ 1000$ deductible rather than $\$ 100,000$ policy with a $\$ 500$ deductible if she was presented with a clear explanation of the types of tradeoffs that would have to be made in choosing between the two policies and the impact to her resources if a fire destroyed her $\$ 150,000$ house and she only had $\$ 100,000$ worth of insurance.

\section{Take advantage of social settings}

There are vast advantages to conducting consumer education in groups, rather than in the normal one-on-one relationship between seller (insurance agent) and prospective buyer (policyholder). Social facilitation increases engagement in learning. People learn even more by teaching one another. Misunderstandings are given voice and can more easily be corrected. Finally, the group conclusions are more readily adopted as social norms.

\section{References}

Anderson, N. H., \& Shanteau, J.C. (1970). Information integration in risky decision making. Journal of Experimental Psychology, 84, 441-451.

Arrow, K. J. (1951). Social choice and individual values. Yale University: Cowles Foundation for Research in Economics, Monograph 12.

Braun, M., Fader, P. S., Bradlow, E. T. \& Kunreuther, H. (2006). Modeling the "pseudodeductible" in insurance claims decisions. Management Science, in press.

Breault, K. D. (1983). Psychophysical measurement and the validity of the modern economic approach: A presentation of methods and preliminary experiments. Social Science Research, $12,187-203$. 
Camerer, C. \& Kunreuther, H. (1989). Decision processes for low-probability events: Policy implications. Journal of Policy Analysis and Management, 8, 565-592.

Cantor, J. \& Engle, R.W. (1993). Working memory capacity as long-term memory activation: An individual-differences approach. Journal of Expeimental Psychology: Learning, Memory and Cognition, 19, 1101-1114.

Chapman, G. B. \& Johnson, E. J. (1995). Preference reversals in monetary and life expectancy evaluations. Organizational Behavior and Human Decision Processes, 62, 300-317.

Condorcet, M. d. (1785). Essai sur l'application do l'analyse à la probabilité des décisions rendues à la pluralit 33 ? des voix. Paris.

Cummins, J. D., McGill, D.M., Winklevoss, H.E. \& Zelten, R.A. (1974). Consumer attitudes toward auto and homeowners insurance. Philadelphia: Wharton School, University of Pennsylvania.

Debreu, G. (1960). Topological methods in cardinal utility theory. In J. A. P. S. S. K. K. (Ed.), Mathematical methods in the social sciences (pp. 16-26). Stanford: Stanford University Press.

Edwards, W. \& von Winterfeldt, D. (1987). Public values in risk debates. Risk Analysis, 7, 141-158.

Finucane, M. L., Alhakami, A., Slovic, P., \& Johnson, S. M. (2000). The affect heuristic in judgments of risks and benefits. Journal of Behavioral Decision Making, 13(1), 1-17.

Fong, G.T., Krantz, D.H., \& Nisbett, R.E. (1986). The effects of statistical training on thinking about everyday problems. Cognitive Psychology, 18, 253-292.

Galanter, E. (1962). The direct measurement of utility and subjective probability. American Journal of Psychology, 75, 208-220.

Green, P. E. \& Srinivasan, V. (1978). Conjoint analysis in consumer research: Issues and outlook. Journal of Consumer Research, 5, 103-123.

Gustaffsson, A., Hermann, A. \& Huber, F. (Eds.). (2000). Conjoint measurement: Methods and applications. Berlin; New York: Springer-Verlag.

Hertwig, R., Barron, G., Weber, E.U. \& Erev, I. (2004). Decisions from experience and the effect of rare events. Psychological Science, 15, 534-539.

Hsee, C. K. \& Kunreuther, H. (2000). The affection effect in insurance decisions. Journal of Risk and Uncertainty, 20, 149-159.

Huber, O., Wider, R., \& Huber, O. (1997). Active information search and complete information presentation in naturalistic risky decision tasks. Acta Psychologica, 95, 15-29.

Johnson, E., Hershey, J., Meszaros, J. \& Kunreuther, H. (1993). Framing, probability distortions, and insurance decisions. Journal of Risk and Uncertainty, 7, 35-51.

Kahneman, D. \& Tversky, A. (1984). Choices, values and frames. American Psychologist, 39, 341-350.

Keeney, R. L. \& Raiffa, H. (1976). Decisions with multiple objectives: Preferences and value tradeoffs. New York: Wiley. 
Köbberling, V. \& Wakker, P. P. (2004). A simple tool for qualitatively testing, quantitatively measuring, and normatively justifying savage's subjective expected utility. Journal of Risk and Uncertainty, 28, 135-145.

Krantz, D. H. (1991). From indices to mappings: The representational approach to measurement. In D. R. B. J. E. K. Smith (Ed.), Frontiers of mathematical psychology: Essays in honor of Clyde Coombs. New York: Springer-Verlag.

Krantz, D. H., Luce, R.D., Suppes, P. \& Tversky, A. (1971). Foundations of measurement Vol. I, Additive and polynomial representations. New York: Academic Press.

Kunreuther, H. (1978). Disaster insurance protection: Public policy lessons. New York: Wiley \& Sons.

Kunreuther, H. \& Hogarth, R. (1995). Decision making under-ignorance: Arguing with yourself. Journal of Risk and Uncertainty, 10(1), 15-36.

Kunreuther, H. \& Pauly, M. (2006). Insurance decision-making and market behavior. Boston, MA: Now Publishers, Inc.

Kunreuther, H., Sanderson, W. \& Vetschera, R. (1985). A behavioral model of the adoption of protective activities. Journal of Economic Behavior and Organization, V, PP

Lewin, K. (1951). Field theory in social science. Oxford: Harpers.

Loewenstein, G. F., Weber, Elke U., Hsee, C. K. \& Welch, N. (2001). Risk as feelings. Psychological Bulletin, 127, 267-286.

Miller, G., Galanter, E. \& Pribram, K. (1960). Plans and the structure of behavior. New York: Holt, Rinehart and Winston.

Newell, A. (1990). Unified theories of cognition. Cambridge: Harvard Univ. Press

Novemsky, N. \& Kahneman, D. (2005). The boundries of loss aversion. Journal of Marketing Research, 42, 139-140.

Payne, J. W., Bettman, J. R. \& Johnson, E. J. (1993). The adaptive decision maker. New York: Cambridge University Press.

Piao, X. \& Kunreuther, H. (2006). Object-oriented affect in warranty decisions. Manuscript: Columbia University.

Piao, X., Kunreuther, H \& Krantz, D. (2006). Improving rationality of insurance choices. Manuscript: Columbia University.

Rabin, M. (2000). Diminishing marginal utility of wealth cannot explain risk aversion. In D. K. a. A. Tversky (Ed.), Choices, values and frames (pp. 202-208). New York: Cambridge University Press.

Riad, J. K., Norris, F.H. \& Ruback, R. B. (1999). Predicting evacuation in two major disasters: Risk perception, social influence and access to resources. Journal of Applied Social Psychology, 29, 918-934.

Savage, L. J. (1954). The foundation of statistics. New York: Wiley.

Seaver, D. A., von Winterfeldt, D. \& Edwards, W. (1978). Eliciting subjective probability distributions on continuous variables. Organizational Behavior and Human Performance, 21, 379-391. 
Sedikides, C., Ariely, D. \& Olsen, N. (1999). Contextual and procedural determinants of partner selection: Of asymmetric dominance and prominence. Social Cognition, 17, 118-139.

See, K., Heath, C., \& Fox, C. (2006). Motivating individual performance with challenging goals: Is it better to stretch a little or a lot? Manuscript: New York University

Seifert, C.M., Hammond, K.J., Johnson, H.M., Converse, T.M., McDougal, T.F., \& Vanderstoep, S.W. (2002). Case-based learning: predictive features in indexing. In Polk, T.A. \& Seifert, C.M. (Eds.), Cognitive Modeling (Pp. 987-1007). Cambridge: MIT Press.

Shafir, E., Simonson, I. \& Tversky, A. (1993). Reason-based choice. Cognition, 49, 11-36.

Shapira, Z. (1995) Risk taking: A managerial perspective. New York: Russell Sage Foundation

Slovic, P. (1995). The construction of preference. American Psychologist, 50, 364-371.

Sydnor, J. (2006). Sweating the small stuff: The demand for low deductibles in homeowners insurance. Manuscript: University of California, Berkeley.

Thaler, R. (1999). Mental accounting matters. Journal of Behavioral Decision Making, 12, 183-206.

Tversky, A. (1967). Utility theory and additivity analysis of risky choices. Journal of Experimental Psychology, 75, 27-36.

Tversky, A. (1969). Intransitivity of preferences. Psychological Review, 76, 31-48.

Tversky, A. \& Kahneman, D. (1979). Prospect theory: An analysis of decision under risk. Econometrica, 47, 263-292.

Tversky, A. \& Kahneman, D. (1992). Advances in prospect theory: Cumulative representation of uncertainty. Journal of Risk and Uncertainty(5), 297-323.

Tversky, A. \& Koehler, D. J. (1994). Support theory: A nonextensional representation of subjective probability. Psychological Review, 101, 547-567.

Tversky, A., Sattath, S. \& Slovic, P. (1988). Contingent weighting and judgment and choice. Psychological Review, 95, 371-384.

Tversky, A., Slovic, P. and Kahneman, D. (1990). The causes of preference reversal. American Economic Review, 80, 204-217.

Zhang, S. \& Markman, A. B. (2001). Processing product unique features: Alignability and involvement in preference construction. Journal of Consumer Psychology, 11(1), 13-27. 